Cochrane Database of Systematic Reviews

\title{
Prompts to encourage appointment attendance for people with serious mental illness (Review)
}

Reda S, Rowett M, Makhoul S

Reda S, Rowett M, Makhoul S.

Prompts to encourage appointment attendance for people with serious mental illness.

Cochrane Database of Systematic Reviews 2001, Issue 2. Art. No.: CD002085.

DOI: 10.1002/14651858.CD002085.

www.cochranelibrary.com

Prompts to encourage appointment attendance for people with serious mental illness (Review) 
TABLE OF CONTENTS

HEADER 1

ABSTRACT

PLAIN LANGUAGE SUMMARY

SUMMARY OF FINDINGS

BACKGROUND

OBJECTIVES

METHODS

RESULTS

Figure 1.

Figure 2.

Figure 3.

DISCUSSION

AUTHORS' CONCLUSIONS

ACKNOWLEDGEMENTS

REFERENCES

CHARACTERISTICS OF STUDIES

DATA AND ANALYSES

Analysis 1.1. Comparison 1 PROMPT TYPE versus NO PROMPT, Outcome 1 Did not attend appointment.

Analysis 2.1. Comparison 2 TELEPHONE PROMPTS versus TEXT-BASED PROMPTS (ORIENTATION STATEMENT), Outcome 1 Did not attend appointment.

Analysis 3.1. Comparison 3 TEXT LETTER PROMPT versus TEXT ORIENTATION STATEMENT, Outcome 1 Did not attend appointment.

Analysis 4.1. Comparison 4 ANY PROMPT versus NO PROMPT, Outcome 1 Did not attend appointment. ADDITIONAL TABLES

APPENDICES

WHAT'S NEW

HISTORY

CONTRIBUTIONS OF AUTHORS

DECLARATIONS OF INTEREST

SOURCES OF SUPPORT

DIFFERENCES BETWEEN PROTOCOL AND REVIEW

INDEX TERMS 
[Intervention Review]

\section{Prompts to encourage appointment attendance for people with serious mental illness}

Sawsan Reda1 ${ }^{1}$ Matthew Rowett ${ }^{2}$, Samer Makhoul ${ }^{3}$

1Guildford, UK. 2St Georges Park Hospital, Northumberland, UK. ${ }^{3}$ Adult Psychiatry, Modern Psychiatry Clinic, Damascus, Syrian Arab Republic

Contact address: Matthew Rowett, St Georges Park Hospital, Morpeth, Northumberland, NE61 2NU, UK. mrowett@live.co.uk.

Editorial group: Cochrane Schizophrenia Group

Publication status and date: Edited (no change to conclusions), published in Issue 8, 2012.

Citation: Reda S, Rowett M, Makhoul S. Prompts to encourage appointment attendance for people with serious mental illness. Cochrane Database of Systematic Reviews 2001, Issue 2. Art. No.: CD002085. DOI: 10.1002/14651858.CD002085.

Copyright @ 2012 The Cochrane Collaboration. Published by John Wiley \& Sons, Ltd.

\section{A B S T R A C T}

\section{Background}

Prompts to encourage attendance at clinics are often used in day-to-day practice by diligent carers of people with mental health problems. These may take the form of telephone prompting, financial incentives or issuing a copy of the referral letter to the appointee.

\section{Objectives}

To estimate the effects of simple prompting by professional carers to encourage attendance at clinics for those with suspected serious mental illness.

\section{Search methods}

We searched the Cochrane Schizophrenia Group Trials Register (April 2009) and reference lists, as well as contacting authors of studies. We updated this search on 17 May 2012 and added the results to the awaiting classification section of the review.

\section{Selection criteria}

All relevant randomised (or quasi-randomised) studies comparing the addition of 'prompts' to standard care for those with serious mental illnesses such as schizophrenia. Prompts had the stated purpose of encouraging attendance or contact with mental health teams and could be text-based, (for example in the form of a letter), electronic, by telephone call, by personal visit, or could employ financial or other rewards.

\section{Data collection and analysis}

Studies and data were independently selected and extracted. For homogeneous dichotomous data the random effects relative risk (RR), the 95\% confidence intervals $(\mathrm{Cl})$ and, where appropriate, the number needed to treat (NNT) were calculated on an intention-to-treat basis. For continuous data the reviewers calculated weighted mean differences.

\section{Main results}

Only four relevant trials were identified (total $n=789$ ). It is not clear whether there is any real difference between attendance of those prompted by telephone one or two days before the appointment, and those given the standard appointment management system (2 RCTs, $\mathrm{n}=457$, RR missed appointment $0.84 \mathrm{Cl} 0.7$ to 1.1 ). Text-based prompts in the form of a letter, a few days before the appointment day, may increase clinic attendance when compared with no prompt ( $3 \mathrm{RCTs}, \mathrm{n}=326$, RR missed appointment $0.76 \mathrm{Cl} 0.43$ to 1.32 ). Only one small study $(n=61)$ reported data on the combination of telephone and text-based prompts versus no prompt, no real difference between groups was apparent (RR missed appointment $0.7 \mathrm{Cl} 0.4$ to 1.2). When telephone prompts were compared with text-based prompts (1 RCT, $\mathrm{n}=75$ ), the latter, in the form of an 'orientation statement' (a short paragraph, taking about 30 seconds to read, explaining the programme 
of care, the fee system, and providing gentle encouragement) may be somewhat more effective than the telephone prompt (RR missed appointment $1.9 \mathrm{Cl} 0.98$ to 3.8). One study ( $n=120)$ compared a standard letter prompt with a letter 'orientation statement'. Overall, results tended to favour the orientation statement approach rather than the simple letter prompting attendance but the results did not reach conventional levels of statistical significance (RR missed appointment $1.6 \mathrm{Cl} 0.9$ to 2.9). When prompts were considered regardless of their type, the results were of greater significance and suggested an effect to increase the rate of attendance (RR missed appointments $0.80 \mathrm{Cl}$ 0.65 to 0.98 ). The inclusion of five new studies to the awaiting classification section may affect results when assessed.

\section{Authors' conclusions}

There is evidence that a simple prompt to attend clinic, very close to the time of the appointment may encourage attendance, and a simple orientation-type letter may be more effective than a telephone prompt. This simple intervention could be a more cost effective means of encouraging compliance at first attendance, but supplementing these data with the results of large, well designed, conducted and reported randomised studies would be desirable.

\section{PLAIN LANGUAGE SUMMARY}

\section{Prompts to encourage appointment attendance for people with serious mental illness}

First appointments at a mental health clinic can be a daunting prospect. Failure to attend is common, wastes time, and can result in important delays in getting proper care. A gentle prompt, near to the time of appointment, would, if effective, seem a cost effective way of encouraging attendance. This review sought evidence for the effects of telephoning or sending a letter, in the days just before the appointment. Relevant studies were found, and although none were conclusive, all suggested that a simple prompt could indeed encourage attendance. 


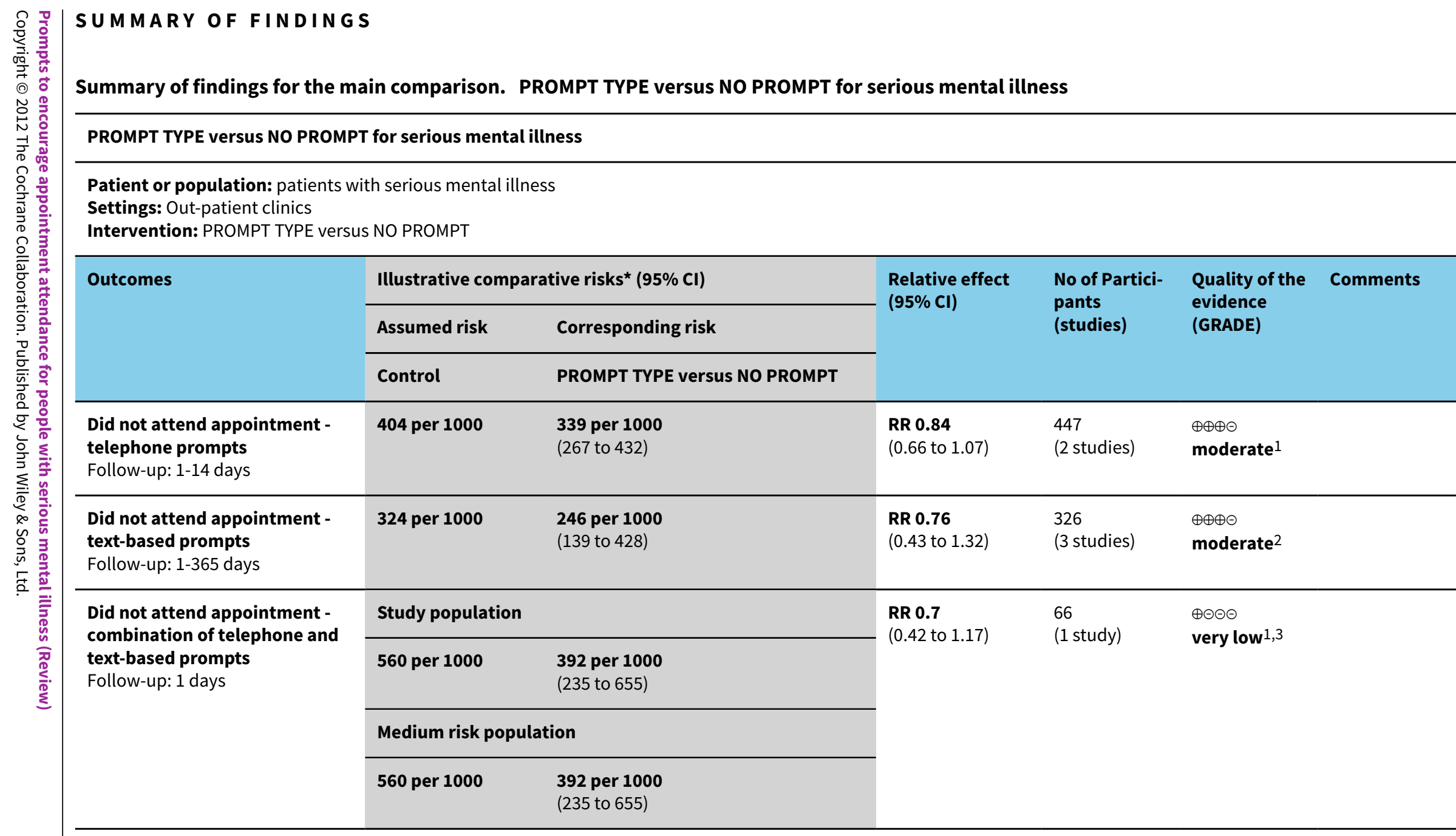

${ }^{*}$ The basis for the assumed risk (e.g. the median control group risk across studies) is provided in footnotes. The corresponding risk (and its $95 \%$ confidence interval) is based on the assumed risk in the comparison group and the relative effect of the intervention (and its $95 \% \mathrm{Cl}$ ).

CI: Confidence interval; RR: Risk ratio;

GRADE Working Group grades of evidence

High quality: Further research is very unlikely to change our confidence in the estimate of effect.

Moderate quality: Further research is likely to have an important impact on our confidence in the estimate of effect and may change the estimate.

Low quality: Further research is very likely to have an important impact on our confidence in the estimate of effect and is likely to change the estimate.

Very low quality: We are very uncertain about the estimate. 


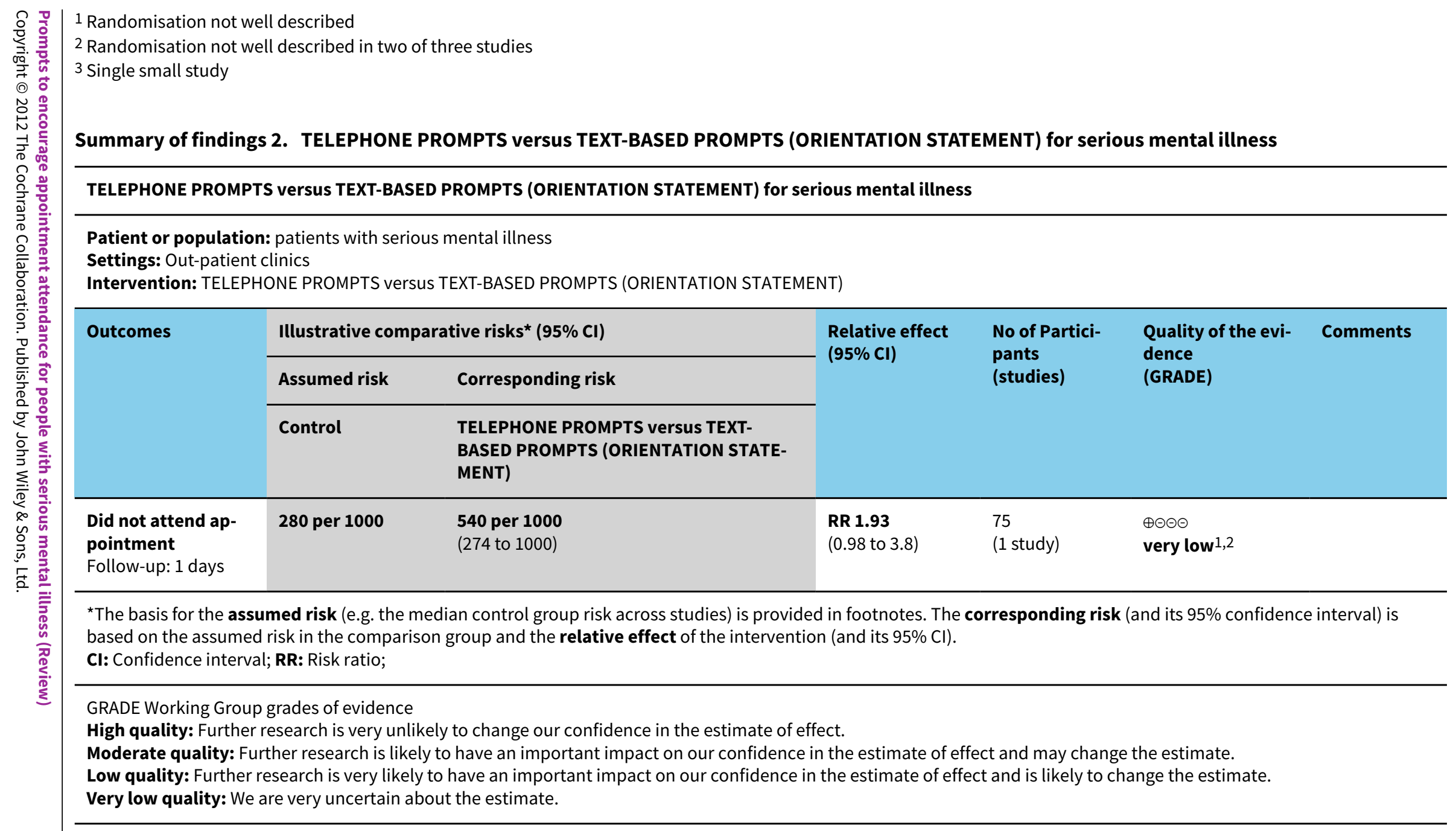

1 Randomisation not well described

2 Single small study

\section{Summary of findings 3. TEXT LETTER PROMPT versus TEXT ORIENTATION STATEMENT for serious mental illness}

\section{TEXT LETTER PROMPT versus TEXT ORIENTATION STATEMENT for serious mental illness}




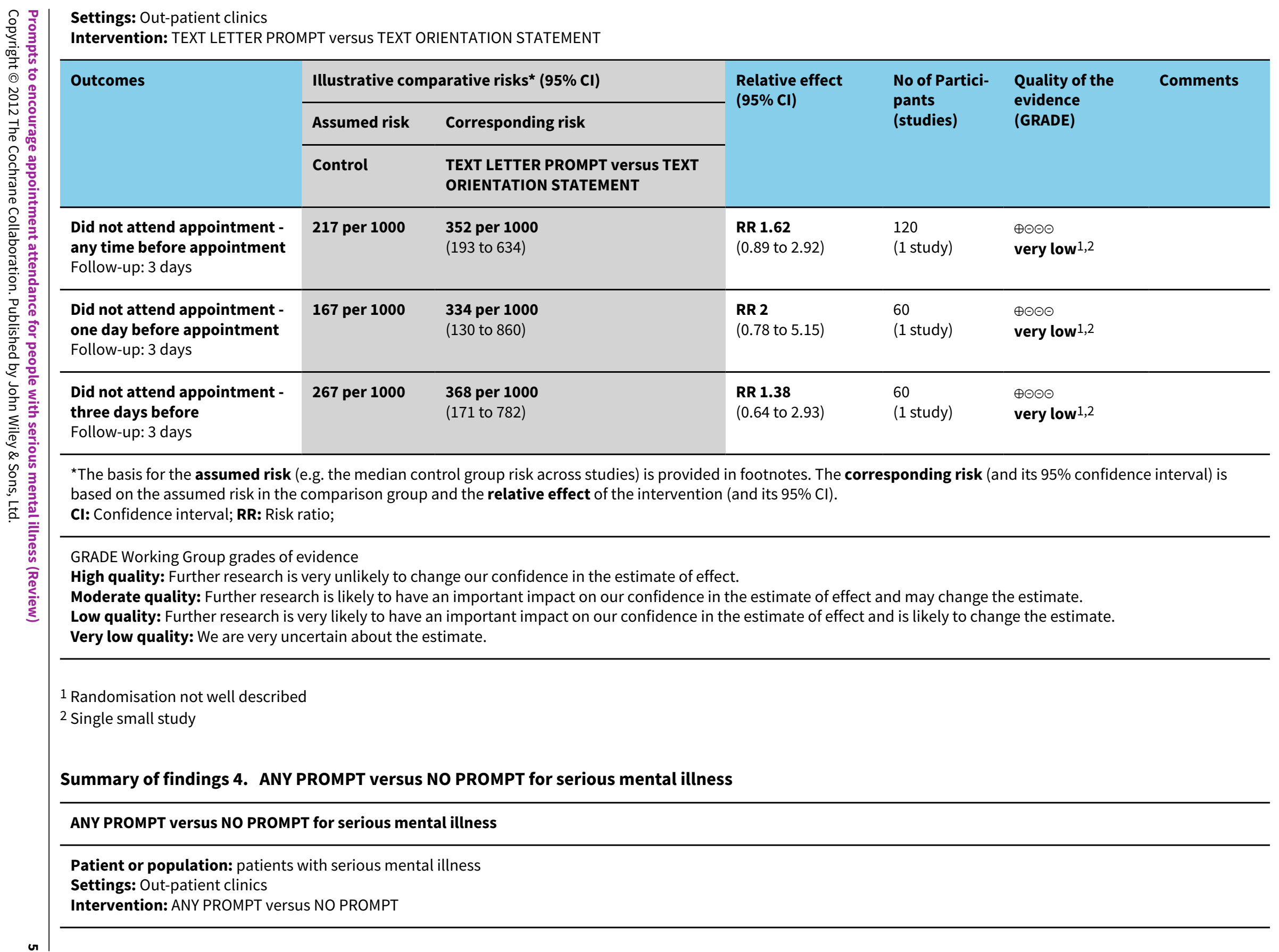

*The basis for the assumed risk (e.g. the median control group risk across studies) is provided in footnotes. The corresponding risk (and its $95 \%$ confidence interval) is based on the assumed risk in the comparison group and the relative effect of the intervention (and its $95 \% \mathrm{Cl}$ ).

GRADE Working Group grades of evidence

High quality: Further research is very unlikely to change our confidence in the estimate of effect.

Moderate quality: Further research is likely to have an important impact on our confidence in the estimate of effect and may change the estimate.

Low quality: Further research is very likely to have an important impact on our confidence in the estimate of effect and is likely to change the estimate. 


\begin{tabular}{|c|c|c|c|c|c|c|c|}
\hline \multirow{3}{*}{\multicolumn{2}{|c|}{ 官 물 }} & \multicolumn{2}{|c|}{ Illustrative comparative risks* $(95 \% \mathrm{Cl})$} & \multirow{3}{*}{$\begin{array}{l}\text { Relative effect } \\
(95 \% \mathrm{CI})\end{array}$} & \multirow{3}{*}{$\begin{array}{l}\text { No of Participants } \\
\text { (studies) }\end{array}$} & \multirow{3}{*}{$\begin{array}{l}\text { Quality of the evi- } \\
\text { dence } \\
\text { (GRADE) }\end{array}$} & \multirow[t]{3}{*}{ Comments } \\
\hline & & Assumed risk & Corresponding risk & & & & \\
\hline & & Control & $\begin{array}{l}\text { ANY PROMPT versus NO } \\
\text { PROMPT }\end{array}$ & & & & \\
\hline 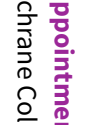 & $\begin{array}{l}\text { Did not attend appoint- } \\
\text { ment } \\
\text { Follow-up: } 1-365 \text { days }\end{array}$ & 361 per 1000 & $\begin{array}{l}\mathbf{2 8 9} \text { per } \mathbf{1 0 0 0} \\
\text { (235 to } 354)\end{array}$ & $\begin{array}{l}\text { RR } 0.8 \\
\text { (0.65 to } 0.98)\end{array}$ & $\begin{array}{l}789 \\
\text { (4 studies) }\end{array}$ & $\begin{array}{l}\oplus \oplus \oplus \ominus \\
\text { moderate }^{1}\end{array}$ & \\
\hline
\end{tabular}

*The basis for the assumed risk (e.g. the median control group risk across studies) is provided in footnotes. The corresponding risk (and its $95 \%$ confidence interval) is based on the assumed risk in the comparison group and the relative effect of the intervention (and its $95 \% \mathrm{Cl}$ ).

Cl: Confidence interval; RR: Risk ratio;

GRADE Working Group grades of evidence

High quality: Further research is very unlikely to change our confidence in the estimate of effect.

Moderate quality: Further research is likely to have an important impact on our confidence in the estimate of effect and may change the estimate.

Low quality: Further research is very likely to have an important impact on our confidence in the estimate of effect and is likely to change the estimate.

Very low quality: We are very uncertain about the estimate.

1 Quality of reporting of randomisation varied 


\section{B A C K G R O U N D}

\section{Description of the condition}

A delicate balance must be struck in the care of those with serious mental health problems. On one hand a person's right to autonomy and privacy must be respected, and on the other, illnesses that erode insight and cause a downward spiral in quality of life have to be managed (Mechanic 1997). Effective management of those with severe mental health problems is often difficult to achieve when those most in need of care can be the hardest to approach (Tyrer 1999). Even early on in a person's illness, if initial support and treatment are not provided, people are rendered more vulnerable to relapse (Commander 1997).

It is difficult to measure the effects of poor clinic/follow-up attendance for people with serious mental illness, their carers and society. A survey in the UK showed that every week each family practitioner in the country has at least four appointments for consultations made but not attended. This leads to longer waiting times for other patients (NHS 1995). The situation may be worse for those with mental health problems. Compliance at clinic is especially important for those with severe mental illness, since those who drop out after their first contact may experience significant deterioration in their mental state (Killaspy 1999, Killaspy 2000) and are more likely to require compulsory admissions (Turner 1998).

Several patient characteristics amongst those with serious mental illness are associated with poor treatment compliance. For example, one study indicated that factors suggesting some stability in a person's life, such as having a telephone, correlated more closely with treatment compliance than general demographic, socio-economic or clinical variables (Hershorn 1993). Another, later investigation suggested that increased compliance is associated with good patient satisfaction, high levels of supervision, the patient having a positive view of the disorder and stable family circumstances (Barnard 1998). Decrease in compliance is to be expected when the treatment regimen is complex, and when factors such as adverse effects, social isolation, substance abuse and increased duration of therapy are involved (Little 1991, Barnard 1998).

\section{Description of the intervention}

Prompts to encourage attendance at clinics, or compliance with medication, are often used in day-to-day practice by diligent carers. These may take the form of telephone prompting (Burgoyne 1983) with or without specific visits to the home (Thi Phan 1995). Sometimes financial incentives are employed (Giuffrida 1997). Issuing a copy of the referral letter to the appointee may prompt attendance for the initial appointment (Hamilton 1999). All such prompts may be embedded within complex care packages, especially for those with ongoing illness. The value of the element of prompt is, however, unclear (Smoller 1998) and there are no guidelines that describe when prompts should be employed. This is especially topical where mental health strategies strive to ensure close supervision of mentally ill people either in hospital or local clinics (DoH 1998).

\section{How the intervention might work}

Simple reminders should encourage people to attend but, equally, could be seen as intrusive by people who are sensitive to contact from hospital.

\section{Why it is important to do this review}

This review substantially updates and improves on what has gone before (Reda 2001).

\section{O B JECT IVES}

Primary objective

To estimate the effects of simple prompting by professional carers to encourage compliance with clinic attendance for those with serious mental illness.

Secondary objective

To establish the value of prompts given to those awaiting their first psychiatric assessment.

\section{METHODS}

\section{Criteria for considering studies for this review}

\section{Types of studies}

All relevant randomised controlled trials. Where a trial was described as 'double-blind' but it was implied that the study was randomised, these trials were classified as quasi-randomised, as were those where allocation was by day of week or alphabetically. Quasi-randomised studies were presented only in the absence of any data from randomised studies.

\section{Types of participants}

Anyone having been diagnosed with, or suspected of, a serious mental illness such as schizophrenia or schizophrenia-like illnesses, diagnosed by any criteria.

\section{Types of interventions}

1. In addition to standard care, any prompt or combination of prompts, whether text-based in the form of a letter, electronic, by telephone call, personal visit, financial or other rewards that has the stated purpose of encouraging attendance.

2. Standard care.

\section{Types of outcome measures}

Outcomes were divided into short term (less than three months) medium term (3-12 months) and long term (more than one year) when prompts were continuing and the same periods after prompting was ended.

\section{Primary outcomes}

The principal outcome measures are classified under two categories.

\author{
1. Service utilisation \\ 1.1 Attendance for review \\ 1.2 Admitted to hospital \\ 1.3 Time to seeing psychiatrist \\ 1.4 Mean days spent in hospital per month
}

2. Compliance

Prompts to encourage appointment attendance for people with serious mental illness (Review)

Copyright $\odot 2012$ The Cochrane Collaboration. Published by John Wiley \& Sons, Ltd. 
2.1 Loss to follow up - loss of contact with the psychiatric care team (including loss to follow in outpatients and failure of psychiatric team to re-establish contact)

2.2 Compliance with medication

\section{Secondary outcomes}

Other outcomes examined were classified under seven categories.

1. Death (suicides, all causes)

2. Service utilisation

2.1 Number of contacts with own doctor for mental illness problems

2.2 Number of contacts with psychiatric services

2.3 Crisis attendance

3. Social functioning

3.1 General

3.2 Specific - imprisonment

3.3 Specific - employment

3.4 Specific - accommodation status

4. Mental state

4.1 General

4.2 Specific - psychological well-being

4.3 Specific - self esteem

5. Quality of life

6. Satisfaction

6.1 Number of needs for care

6.2 Patient satisfaction

6.3 Carer satisfaction

7. Costs

7.1 Direct costs

7.2 Indirect costs

\section{Search methods for identification of studies}

\section{Electronic searches}

1. Cochrane Schizophrenia Group Trials Register (April 2009)

The register was searched using the phrase:

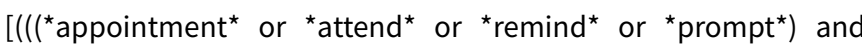

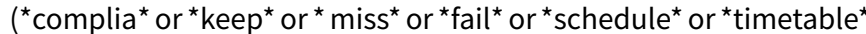
or ${ }^{\star}$ letter ${ }^{\star}$ or ${ }^{*}$ phone ${ }^{\star}$ or ${ }^{\star}$ text $^{\star}$ or ${ }^{\star}$ email ${ }^{\star}$ or ${ }^{*}$ e-mail ${ }^{\star}$ or ${ }^{*}$ sms $^{\star}$ or ${ }^{\star}$ visit $^{\star}$ or call* or * system*)) or * patient complia* or * patient drop* or *outpatient clinics* or *outpatient care* or *outpatient service or *outpatient treatment* or *treatment-complian* or * treatment complian* or * client character ${ }^{\star}$ or *motivation* or *absente ${ }^{\star}$ ) in title, abstract and index terms of Reference or (remind ${ }^{\star}$ or prompt $^{\star}$ or ${ }^{\star}$ phone ${ }^{\star}$ or letter ${ }^{\star}$ or appointment ${ }^{\star}$ ) in interventions of Study]

This register is compiled by systematic searches of major databases, hand searches and conference proceedings.

\section{Cochrane Schizophrenia Group Trials Register (May 2012)}

We updated this search. The Trials Search Co-ordinator, Samantha Roberts searched the Cochrane Schizophrenia Group's Trials Register (17 May 2012).
The Cochrane Schizophrenia Group's Trials Register is compiled by systematic searches of major databases, handsearches and conference proceedings (see group module).

Trials identified through the searching activities are each assigned to awaiting classification of relevant review titles.

\section{Details of other previous searches are seen in Appendix 1}

\section{Searching other resources}

1. Reference lists

Examination of references cited in all included trials were searched in order to identify further relevant trials.

2. ISI database - Science Citation Index and Social Science Citation Index

Each of the included studies was sought as a cited reference on the above databases. Reports of articles that had cited these studies were inspected in order to identify further trials.

\section{Personal contact}

The authors of all the studies initially selected for inclusion were contacted in order to identify any missing relevant trials.

\section{Hand Searching}

High yield journals were to have been identified by electronic searches and, if available, and not already hand searched, two journals would have been chosen for full, page by page, inspection. In the event, no high yield journals were identified.

\section{Data collection and analysis}

The reviewers read the Cochrane Handbook (Higgins 2008), and acquired training by attending relevant workshops and contacting the Editorial Base/Editor as required.

\section{Selection of studies}

The reviewers (SR, MR, SM) independently inspected all reports of identified studies. It was usually possible to resolve any disagreement by consensus; however, where doubt remained the full article was acquired. The reviewers independently decided whether these met the review criteria. No blinding to the names of authors, institutions and journal of publication took place. Again, any disagreements were resolved by consensus. When this proved impossible, further information was sought and, in the interim, these trials were added to 'Awaiting assessment' list.

\section{Data extraction and management}

\section{Extraction}

Authors SR, MR and SM independently extracted data from included studies. Again, any disagreement was discussed, decisions documented and, if necessary, authors of studies were contacted for clarification.

\section{Management}

Data were extracted onto standard, simple forms.

3. Scale-derived data

We included continuous data from rating scales only if the measuring instrument had been described in a peer-reviewed journal (Marshall 2000) and the instrument is either a self-report or completed by an independent rater or relative (not the therapist). 


\section{Assessment of risk of bias in included studies}

Again working independently, SR, and MR assessed risk of bias using the tool described in the Cochrane Collaboration Handbook (Higgins 2009). This tool encourages consideration of how the sequence was generated, how allocation was concealed, the integrity of blinding at outcome, the completeness of outcome data, selective reporting and other biases. We would not have included studies where sequence generation was at high risk of bias or where allocation was clearly not concealed. If disputes arose as to which category a trial has to be allocated, again, resolution was made by discussion.

\section{Measures of treatment effect}

1. Binary data

For binary outcomes we calculated a standard estimation of the random-effect risk ratio (RR) and its 95\% confidence interval (CI). For statistically significant results we calculated the number needed to treat/harm statistic (NNT/H), and its 95\% confidence interval (Cl) using Visual Rx (http://www.nntonline.net/) taking account of the event rate in the control group.

\section{Continuous data}

\subsection{Summary statistic}

For continuous outcomes we estimated a random-effect weighted mean difference (WMD) between groups. We did not calculate effect size measures.

\subsection{Endpoint versus change data}

We preferred to use scale endpoint data, which typically cannot have negative values and is easier to interpret from a clinical point of view. Change data are often not ordinal and are very problematic to interpret. If endpoint data were unavailable, we used change data.

\subsection{Skewed data}

Continuous data on clinical and social outcomes are often not normally distributed. To avoid the pitfall of applying parametric tests to non-parametric data, we aim to apply the following standards to all data before inclusion: (a) standard deviations and means are reported in the paper or obtainable from the authors; (b) when a scale starts from the finite number zero, the standard deviation, when multiplied by two, is less than the mean (as otherwise the mean is unlikely to be an appropriate measure of the centre of the distribution, (Altman 1996); (c) if a scale starts from a positive value (such as PANSS which can have values from 30 to $210)$ the calculation described above will be modified to take the scale starting point into account. In these cases skew is present if $2 \mathrm{SD}>(\mathrm{S}-\mathrm{S} \mathrm{min}$ ), where $\mathrm{S}$ is the mean score and $\mathrm{S}$ min is the minimum score. Endpoint scores on scales often have a finite start and end point and these rules can be applied. When continuous data are presented on a scale which includes a possibility of negative values (such as change data), it is difficult to tell whether data are skewed or not. Skewed data from studies of less than 200 participants were entered in additional tables rather than into an analysis. Skewed data pose less of a problem when looking at means if the sample size is large and were entered into syntheses.

\section{Unit of analysis issues}

\section{Cluster trials}

Studies increasingly employ 'cluster randomisation' (such as randomisation by clinician or practice) but analysis and pooling of clustered data poses problems. Firstly, authors often fail to account for intraclass correlation in clustered studies, leading to a 'unit of analysis' error (Divine 1992) whereby $p$ values are spuriously low, confidence intervals unduly narrow and statistical significance overestimated. This causes type I errors (Bland 1997, Gulliford 1999).

Where clustering is not accounted for in primary studies, we presented data in a table, with $\left.a^{*}{ }^{*}\right)$ symbol to indicate the presence of a probable unit of analysis error. In subsequent versions of this review we will seek to contact first authors of studies to obtain intraclass correlation co-efficient of their clustered data and to adjust for this by using accepted methods (Gulliford 1999). Where clustering had been incorporated into the analysis of primary studies, we present these data as if from a non-cluster randomised study, but adjusted for the clustering effect.

We have sought statistical advice and have been advised that the binary data as presented in a report should be divided by a 'design effect'. This is calculated using the mean number of participants per cluster $(\mathrm{m})$ and the intraclass correlation co-efficient (ICC) [Design effect $\left.=1+(m-1)^{\star} I C C\right]$ (Donner 2002). If the ICC was not reported it was assumed to be 0.1 (Ukoumunne 1999).

If cluster studies has been appropriately analysed taking into account intraclass correlation co-efficient and relevant data documented in the report, synthesis with other studies would have been possible using the generic inverse variance technique.

\section{Cross-over trials}

A major concern of cross-over trials is the carryover effect. It occurs if an effect (e.g. pharmacological, physiological or psychological) of the treatment in the first phase is carried over to the second phase. As a consequence on entry to the second phase the participants can differ systematically from their initial state despite a wash-out phase. For the same reason cross-over trials are not appropriate if the condition of interest is unstable (Elbourne 2002). As both effects are very likely in schizophrenia, we will only use data of the first phase of cross-over studies.

\section{Studies with multiple treatment groups}

Where a study involved more than two treatment arms, if relevant, the additional treatment arms were presented in comparisons. Where the additional treatment arms were not relevant, these data were not reproduced.

\section{Dealing with missing data}

\section{Overall loss of credibility}

At some degree of loss of follow up data must lose credibility (Xia 2007). We are forced to make a judgment where this is for the very short-term trials likely to be included in this review. Should more than $40 \%$ of data be unaccounted for by 24 hours we did not reproduce these data or use them within analyses.

\section{Binary}

In the case where attrition for a binary outcome is between 0 and $40 \%$ and outcomes of these people are described, we included these data as reported. Where these data were not clearly described, we assumed the worst primary outcome, and rates of adverse effects similar to those who did continue to have their data recorded.

\section{Continuous}


In the case where attrition for a continuous outcome is between 0 and $40 \%$ and completer-only data were reported, we have reproduced these.

\section{Assessment of heterogeneity}

1. Clinical heterogeneity

We considered all included studies without any comparison to judge clinical heterogeneity.

\section{Statistical}

2.1 Visual inspection

We visually inspected graphs to investigate the possibility of statistical heterogeneity.

2.2 Employing the I-squared statistic

This provided an estimate of the percentage of inconsistency thought to be due to chance. I-squared estimate greater than or equal to $50 \%$ was interpreted as evidence of high levels of heterogeneity (Higgins 2002).

\section{Assessment of reporting biases}

Reporting biases arise when the dissemination of research findings is influenced by the nature and direction of results (Egger 1997). These are described in section 10.1 of the Cochrane Handbook (Higgins 2009). We are aware that funnel plots may be useful in investigating reporting biases but are of limited power to detect small-study effects. We did not use funnel plots for outcomes where there were ten or fewer studies, or where all studies were of similar sizes. In other cases, where funnel plots were possible, we sought statistical advice in their interpretation.

\section{Data synthesis}

Where possible we employed a random-effect model for analyses. We understand that there is no closed argument for preference for use of fixed or random-effect models. The random-effect method incorporates an assumption that the different studies are estimating different, yet related, intervention effects. This does seem true to us, however, random-effect does put added weight onto the smaller of the studies - those trials that are most vulnerable to bias. For this reason we favour using fixedeffect models employing random-effect only when investigating heterogeneity.

\section{Subgroup analysis and investigation of heterogeneity}

If data are clearly heterogeneous we checked that data are correctly extracted and entered and that we had made no unitof-analysis errors. If the high levels of heterogeneity remained we did not undertake a meta-analysis at this point for if there is considerable variation in results, and particularly if there is inconsistency in the direction of effect, it may be misleading to quote an average value for the intervention effect. We would have wanted to explore heterogeneity. We pre-specify no characteristics of studies that may be associated with heterogeneity except quality of trial method. If no clear association could be shown by sorting studies by quality of methods a random-effect meta-analysis was performed. Should another characteristic of the studies be highlighted by the investigation of heterogeneity, perhaps some clinical heterogeneity not hitherto predicted but plausible causes of heterogeneity, these post-hoc reasons will be discussed and the data analysed and presented. However, should the heterogeneity be substantially unaffected by use of random-effect meta-analysis and no other reasons for the heterogeneity be clear, the final data were presented without a meta-analysis.

\section{Sensitivity analysis}

If necessary, we analysed the effect of including studies with high attrition rates in a sensitivity analysis. We aimed to include trials in a sensitivity analysis if they are described as 'doubleblind' but only implied randomisation. If we found no substantive differences within primary outcome when these high attrition and 'implied randomisation' studies were added to the overall results, we included them in the final analysis. However, if there was a substantive difference we only used clearly randomised trials and those with attrition lower than $40 \%$.

\section{RES U LTS}

\section{Description of studies}

\section{Results of the search}

We found 1318 references (586 studies). Despite extensive searches we only found four trials (total $n=789$ ) that could be included. Not one of these studies exclusively reports on the effects of prompts for people with serious mental illnesses (see below).

\section{Included studies}

Only four trials could be included (Burgoyne 1983, Kluger 1983, Swenson 1988, Kitcheman 2008) with a total of 690 participants. While the intent of this review is to look at encouraging attendance at clinic appointments in general, all four included studies looked at attendance at first appointment.

\section{Participants}

No trial met the original inclusion criteria of focusing only on "anyone having been diagnosed with, or suspected of, a serious mental illness such as schizophrenia or schizophrenialike illnesses, diagnosed by any criteria. (Please see 'Discussion: Limited data'). The inclusion of studies where all participants were due to attend their first appointments at community mental health centres and general adult clinics allows some speculation on how prompting may affect attendance of seriously mentally ill people. Certainly, a high proportion of those attending such centres should suffer from undiagnosed serious mental illnesses. While this may result in a more heterogeneous study population, it is more likely to accurately reflect the effects of prompts in the first attender population. The demographic background of the participants in Burgoyne 1983 and Swenson 1988 was not described but people entering the Kluger 1983 study were, on average, in their thirties, over $70 \%$ male and over $60 \%$ from AfricanAmerican or Hispanic background. The Burgoyne 1983 and Kluger 1983 studies were both set in urban North American cities. Swenson 1988 , on the other hand was run from a Community Mental Health Centre that served a small urban and rural population in the Midwest of the USA. Kitcheman 2008 looked at people attending the outpatient clinic for the first time, in seven study clinics for different psychiatric sub-specialities, in an urban population in the north of England. Some of these sub-specialities would have a low rate of serious mental illness such as schizophrenia or schizophrenia-like illnesses. Analysis of data from this study was therefore limited to the general adult clinic sample as it was felt this group would have the higher rate of serious mental illness. The funnel plot in Figure 1 
shows that, prior to the inclusion of this small subgroup, there may have been a publication bias towards positive effects.

Figure 1. Funnel plot of comparison 4: ANY PROMPT versus NO PROMPT, outcome: 4.1 Did not attend appointment.

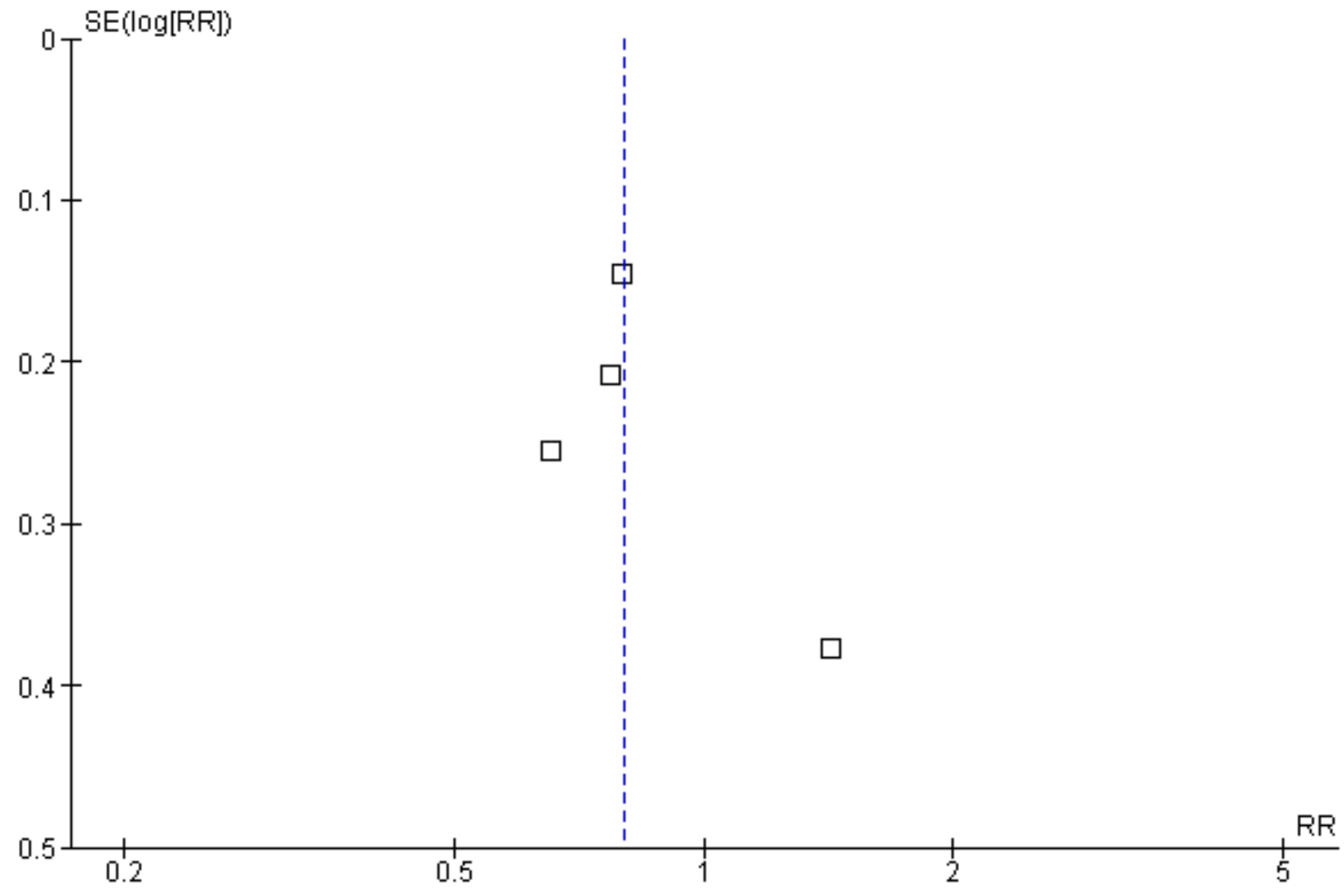

\section{Interventions}

Burgoyne 1983 compared telephone prompt (48 hours before clinic) with a control (no telephone call). Kluger 1983 also compared a telephone prompt, this time 24 hours before clinic, with a control. This study had two additional groups. One received an orientation statement and the other an orientation statement and a telephone call. The orientation statement was a short paragraph, taking about 30 seconds to read, explaining the programme of care, the fee system, and providing gentle encouragement. Swenson 1988 compared a very similar statement delivered either 72 or 24 hours before appointment, with a standard letter prompt, again 72 or 24 hours before the clinic appointment was due. The control group in Swenson 1988 was issued the standard appointment card. Kitcheman 2008 compared an individualised pro-forma letter in the form of an 'orientation statement' (on headed paper explaining the time of the appointment, name of the doctor, description of the clinic and its routine, a map and a request to bring a list of medication and a friend or family member) sent 72 hours before the appointment plus standard care (of either an appointment card within 13 weeks of the appointment or an opt-in partial booking system) with standard care alone.

\section{Outcomes}

All four trials reported attendance as a primary outcome. Burgoyne 1983 , however, reported the outcomes for people with telephones as well as for those without. As people were randomised before it was known whether they had a telephone, and those with telephones were clearly evenly balanced in the two groups, it suggests that the randomisation process was effective. Only these data are presented, as any subtle effect of prompting would be likely to have been masked by the attendance figures for those who could not have received the intervention. Kitcheman 2008 reported a number of secondary outcomes for their total population but did not provide these data for each sub-speciality.

\section{Excluded studies}

1. Excluded studies

Nine of the 22 excluded studies were not randomised. Three appeared to be quasi-randomised (Danoff 1993, Hildebrandt 1975, MacDonald 2000) but only MacDonald 2000 was likely to include a significant number of people with serious mental illnesses. Some randomised trials were excluded because participants were not likely to suffer from serious mental illnesses (Hamilton 1999, Hochstadt 1980, Kourany 1990, Larsen 1979). Others were excluded because the interventions were not simple prompts, in that they were supportive and educational approaches to care, only one part of which was to encourage compliance with care (Cramer 1998, Hornung 1998, Spooren 1998, Zanjani 2008). Two randomised trials had to be excluded because outcome data were not fully reported (Blake 1990, Sharma 1995). Authors of several of these studies have been contacted and further data may make it possible to include important work. 
2. Awaiting assessment

Five studies are awaiting assessment.

3. Ongoing

The reviewers know of no ongoing studies.

\section{Risk of bias in included studies}

The risk of bias summary is shown in Figure 2. Overall, as means of minimising selection bias (randomisation) and observation bias (blinding) were not well described, three studies were considered as having moderate risk of bias (Burgoyne 1983; Kluger 1983; Swenson 1988). The biases are likely to favour the interventions of interest, rather than the control group.

Figure 2. Methodological quality summary: review authors' judgements about each methodological quality item for each included study.

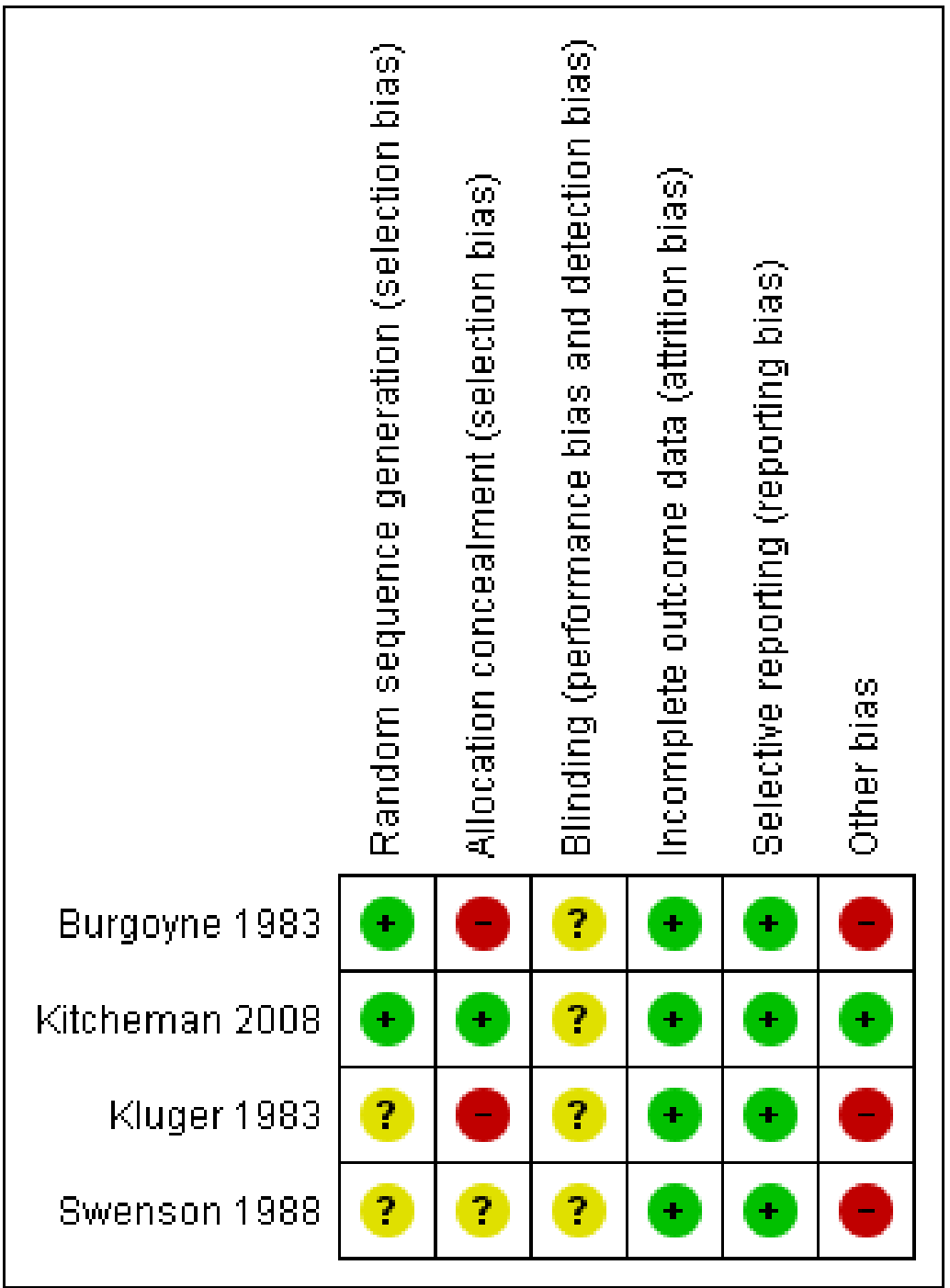

\section{Allocation}

Only one study, (Kitcheman 2008), explicitly described the means of allocation and assured the reader that selection bias was minimised. They used an on-line computer programme for block randomisation and then this sequence was linked to a list of ID numbers, and only then sent to those preparing to send the orientation statements for de-coding.

\section{Blinding}

Burgoyne 1983 stated that raters were not blind to the intervention group to which a person had been allocated. Kitcheman 2008 stated that only the Trial Co-ordinator involved in linking anonymous allocation lists to participant details and then sending the prompts, was aware of allocation. Those seeking outcomes were blind to group of allocation. The other studies did not mention blinding.

\section{Incomplete outcome data}

All people who entered the studies were accounted for in the analyses

\section{Selective reporting}

We found no evidence of selective reporting. 


\section{Other potential sources of bias}

There is no clear source of other biases.

\section{Effects of interventions}

See: Summary of findings for the main comparison PROMPT TYPE versus NO PROMPT for serious mental illness; Summary of findings 2 TELEPHONE PROMPTS versus TEXT-BASED PROMPTS (ORIENTATION STATEMENT) for serious mental illness; Summary of findings 3 TEXT LETTER PROMPT versus TEXT ORIENTATION STATEMENT for serious mental illness; Summary of findings 4 ANY PROMPT versus NO PROMPT for serious mental illness

1. COMPARISON 1. PROMPT BY TYPE versus NO PROMPT (Summary of findings for the main comparison)

Telephone and text-based prompts were compared separately with 'standard care'. The two were then combined and, again, compared with usual care.

\subsection{Did not attend appointment}

1.1.1 Telephone prompts

Most data are available for telephone prompts ( 2 trials, $n=457$ ). The confidence intervals make it difficult to know whether there were in fact any real differences between attendance of those prompted by telephone one or two days before the appointment, and those given the standard appointment management system (RR missed appointment $0.84 \mathrm{Cl} 0.7$ to 1.1 ).

\subsubsection{Text-based prompts}

Again, confidence intervals make it difficult to know if there is a true effect of a text-based prompt. There were fewer people randomised than in the telephone prompts comparison ( 3 trials, $n=326$ ). Textbased prompts, a few days before the appointment day, appeared to increase clinic attendance but this effect did not make statistical significance (RR missed appointment $0.76 \mathrm{Cl} 0.43$ to 1.32).

1.1.3 Combination of telephone and text-based prompts

Only one study reported data on this comparison (Kluger 1983, $\mathrm{n}=61$ ). Again there is a suggestion of an effect in favour of the prompts but the confidence intervals make it difficult to know whether there was in fact any real difference between the two approaches (RR missed appointments $0.7 \mathrm{Cl} 0.4$ to 1.2).

2. COMPARISON 2. TELEPHONE PROMPT versus TEXT-BASED PROMPTS (ORIENTATION STATEMENT) (Summary of findings 2)
2.1 Did not attend appointment

Kluger 1983 again provided data for this comparison $(n=75)$. A telephone prompt was compared with an 'Orientation statement'. This was a short paragraph, taking about 30 seconds to read, explaining the programme of care, the fee system, and providing gentle encouragement. The results appeared to favour the textbased prompt although, again the result is not quite statistically significant (RR missed appointments $1.9 \mathrm{Cl} 0.98$ to 3.8).

3. COMPARISON 3. TEXT LETTER PROMPT versUS TEXT ORIENTATION STATEMENT PROMPT (Summary of findings 3 ) Only Swenson $1988(n=120)$ provided data for this comparison.

3.1 Did not attend appointment

3.1.1 Any period before appointment

Overall, results tended to favour the orientation statement approach rather than the simple letter prompting attendance (RR missed appointments $1.6 \mathrm{Cl} 0.9$ to 2.9), although this effect fails to reach conventional levels of statistical significance.

\subsubsection{One or three days before appointment}

Subgroups of the same study present data for attendance for those randomised to receive the different interventions one or three days before clinic. No results are statistically significant, but, if anything, there is a suggestion that an orientation-type prompt within a day of appointment may be best.

\section{COMPARISON 4. ANY PROMPT versus NO PROMPT (Summary of} findings 4)

\subsection{Did not attend appointment}

Data for all methods of prompting were combined to give a measure of the effect of any kind of prompt on attendance at first appointment ( 4 trials, $n=789$ ). This gave a statistically significant result in favour of prompts encouraging attendance (Figure 3, RR missed appointments $0.80 \mathrm{Cl} 0.65$ to 0.98). On visual inspection the findings of Kitcheman 2008 seem at odds with those of the earlier studies. We checked the data and found no unit-of-analysis errors. The Kitcheman 2008 study sub-group examined here has a small number of participants resulting in a confidence interval that overlaps with the findings of the earlier studies. The I-squared statistical measure of heterogeneity is only $2 \%$ showing little variability between studies that cannot be explained by chance.

\section{Figure 3. Forest plot of comparison: 4 ANY PROMPT versus NO PROMPT, outcome: 4.1 Did not attend appointment.}

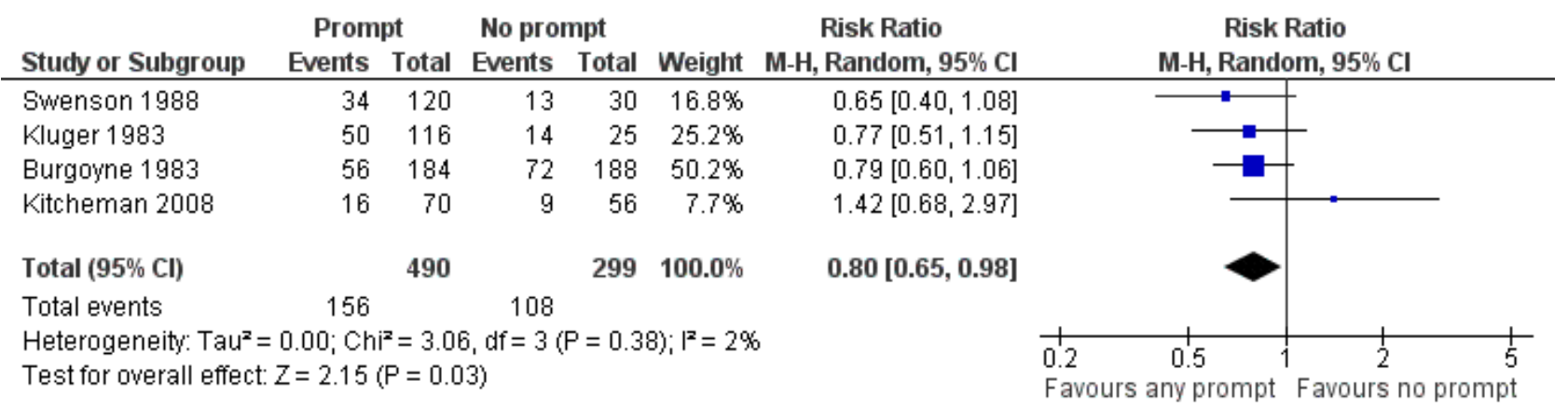




\section{DISCUSSION}

\section{Summary of main results}

\section{COMPARISON 1. PROMPT BY TYPE versus NO PROMPT}

Telephone prompts near to the time of the appointment may have a weak effect and encourage attendance. Even this effect could be very cost-effective, considering financial implications of missed appointments. A large study would be needed to quantify the effect with any confidence. Text-based prompts may also have an effect to reduce non-attendance. Too few data are available to confidently suggest an interaction between the telephone and textbased prompts.

\section{COMPARISON 2. TELEPHONE PROMPT versus TEXT-BASED PROMPT}

The one small trial $(n=75)$ does present data suggesting an effect favouring the text-based orientation statement prompt. Such simple interventions could easily be randomised in many different settings to supplement these data.

3. COMPARISON 3. TEXT LETTER PROMPT versuS TEXT ORIENTATION STATEMENT PROMPT

Data do suggest that a short, encouraging letter, explaining the working of the clinic, presented a day before appointment, may be most effective, but again, it is impossible to be confident as so few people have been randomised and the findings of Swenson 1988 should be replicated.

\section{COMPARISON 4. ANY PROMPT versus NO PROMPT}

Combining data for all prompts gives the strongest indication of an effect of prompting on reducing non-attendance at first appointments (Figure 3). This gives a number needed to treat of 24 . While this is a relatively large number the intervention is cheap and would potentially pay for itself through the reduction in costs associated with non-attendance.

\section{Overall completeness and applicability of evidence}

\section{Completeness}

There were only four studies looking at encouraging appointment attendance that were able to be included in this review. None of these specifically looked at people with serious mental illness. They all looked at attendance at first appointment. While the findings of this review are suggestive of an effect to encourage attendance further studies that specifically identify those with serious mental illness must be performed before the evidence can be said to be complete.

\section{Applicability}

The reviewers know of no other systematic approach to reviewing this area and, although the findings are intriguing, more data are need to support the findings. Only one study is from the UK, the others being from the USA. Three of the studies were set in the inner city and one in a mixed urban-rural environment. The UKbased trial is large overall $(n=764)$ but the sub-group that was specifically likely to be seriously mentally ill is quite small. It is important to ensure that findings are applicable outside of the USA It is also possible, with the proliferation of portable telephones and access to e-mail, that the results of the earlier studies, now mostly nearly two decades old, may underestimate the effect of contact as accessibility of people should now be greater than in the 1980's.
The reviewers eagerly await data to strengthen or refute the current findings.

\section{Quality of the evidence}

1. Limited data

The reviewers did consider at great length whether or not to stray from the protocol and include data from studies that were not specifically about the effects of prompts on the attendance of people with serious mental illnesses such as schizophrenia. After consultation with others, it was decided to include data from the trials that could have included seriously mentally ill people. The reviewers still feel that the original question, 'what are the effects of prompting clinic attendance for those with serous mental illness?' is justified of itself, but decided that including data from trials using broader inclusion criteria, would hopefully generate hypotheses for future work. The results, although not specifically about those with severe mental illness, will be of interest to those deciding whether or not to introduce this intervention on a service wide basis, or in a general psychiatric outpatient system, where those with both severe mental illnesses such as schizophrenia are cared for alongside those with less severe mental illnesses. The addition of five new studies to awaiting assessment may add further data when assessed.

\section{Overall quality}

Only one study described their method of allocation, (Kitcheman 2008). One study did not blind raters to participant allocation, (Burgoyne 1983), and two others did not mention blinding, (Kluger 1983; Swenson 1988). The most methodologically rigorous study, (Kitcheman 2008), only provided a small sub-group that could be included in this review. This limits the quality of the evidence and may effect the findings by favouring the intervention.

\section{Potential biases in the review process}

We are not aware of biases in the review process. We may, however, have failed to identify small studies because of a degree of publishing bias (Egger 1997) operating in this review but do not think we would have not found large relevant studies.

\section{Agreements and disagreements with other studies or reviews}

While the previous Cochrane review, (Reda 2001), suggested an effect to encourage appointment attendance, particularly for a text orientation statement, it did not show a statistically significant effect. This current update has shown a statistically significant effect of prompting people to attend appointments with a 'number needed to treat' of twenty-four people.

\section{AUTHORS' CONCLUSIONS}

\section{Implications for practice}

1. For people with serious mental illness

In an age of mobile telephone text messages, twitter, 'blog', e-mail, social networking systems, letters may seem old fashioned - and may indeed be so. Nevertheless some form of contact to remind people of upcoming clinic appointments my be acceptable and effective. In modern well-organised health service, choices should be available.

\section{For clinicians}


There is evidence that a very simple prompt to attend clinic, very close to the time of the appointment, may encourage attendance even of those who have serious mental illnesses. Data are weak, however, and clinicians could, relatively easily, undertake their own local randomised evaluation of this technique.

\section{For managers and policy makers}

Managers may wish to help avoid the waste of time and expense involved in missed appointments by helping organise an automated system for contacting people. What evidence there is suggests that a simple orientation-type letter, 24 hours before the clinic appointment, may be most effective.

\section{Implications for research}

1. General

Three of the four included studies we found were performed over 20 years ago. The studies of today are usually reported in more detail, thanks to the CONSORT statement (Consolidated Standards of Reporting Trials;CONSORT; Moher 2001). This is intended to improve reporting of randomised controlled trials, enabling readers to understand the design, conduct, analysis and interpretation, and to assess the validity of results. CONSORT emphasises that this can only be achieved through complete transparency from authors.

\section{Specific}

The simple intervention could be an automated and most cost effective means of encouraging compliance at first attendance. With so many clinic appointments missed, and the potential for subsequent deterioration of mental state (Killaspy 1999, Killaspy 2000), supplementing these weak data with the results of a large, well designed, conducted and reported randomised study would be desirable. We are aware that there are difficulties randomising specifically people with serious mental illness in the out-patient setting. We are also aware that because of the focus of this review (people with serious mental illness) we have fragmented the largest study in this area (Kitcheman 2008, $n=764$ ). We do think that more trials are indicated but think that general and broad inclusion criteria would be best but data reporting undertaken in such a way that effects for sub-groups could be analysed separately. We suggest a design in Table 1.

\section{ACK N O WLEDGEMENTS}

The authors would like to thank Dr Spooren who helpfully supplied additional information about his study. Dr MacDonald has been most helpful in providing unpublished data.

We would also like to acknowledge the help of the staff at the Editorial Base of the Cochrane Schizophrenia Group for their support and use of the generic text for much of the 'Methods' section of this review. We have adapted this where appropriate. 
R E F E R E N C E S

\section{References to studies included in this review}

Burgoyne 1983 \{published data only\}

Burgoyne R, Frank A, Yamamoto J. Telephone prompting to increase attendance at a psychiatric outpatient clinic. American Journal of Psychiatry 1983;140:345-7.

\section{Kitcheman 2008 \{published data only\}}

Adams C. Prompting vs no prompting to encourage out patient attendance: Leeds PROMPTS trial. National research register 2005.

Kader I. Prompts to encourage attendance at psychiatric outpatient appointments - a randomised controlled trial: the Leeds prompts study. Schizophrenia Research 2004;67:193.

* Kitcheman J, Adams CE, Pervaiz A, Kader I, Mohandas D, Brookes G. Does an encouraging letter encourage attendance at psychiatric out-patient clinics? The Leeds PROMPTS randomised study. Psychological Medicine 2008;38(5):717-23.

Kluger 1983 \{published data only\}

Kluger M, Karras A. Strategies for reducing missed initial appointments in a community mental health centre. Community Mental Health Journal 1983;19(2):137-43.

\section{Swenson 1988 \{published data only\}}

Swenson T, Pekarik G. Interventions for reducing missed initial appointment at a community mental health centre. Community Mental Health Journal 1988;24(3):205-18.

\section{References to studies excluded from this review}

Bende 1991 \{published data only\}

Bende K, Koshy M. Returning for follow-up attendance compliance in an Indian psychiatric clinic. International Journal of Social Psychiatry 1991;37(3):173-81.

Blake 1990 \{published data only\}

Blake D, Owens M, Keane T. Increasing group attendance on a psychiatric unit: an alternating treatments design comparison. Journal of Behavioural, Therapeutic and Experimental Psychiatry 1990;21(1):15-20.

Blouin 1985 \{published data only\}

Blouin A, Perez E, Minoletti A. Compliance to referrals from the psychiatric emergency room. Canadian Journal of Psychiatry 1985;30:103-6

\section{Cramer 1998 \{published data only\}}

Cramer JA, Rosenheck R. Compliance with medication regimens for psychiatric and medical disorders. Psychiatric Services 1998;49:196-210.

\section{Danoff 1993 \{published data only\}}

Danoff N, Kemper K. Does excluding patients without telephones affect the results of telephone reminder studies?. Western Journal of Medicine 1993;158(1):44-6.
Deane 1991 \{published data only\}

Deane F. Improving attendance at intake in children's outpatient services of a community mental health centre. Child Care, Health and Development 1991;17:115-21.

Hamilton 1999 \{published data only\}

Hamilton W, Round A, Sharp D. Effect on hospital attendance rates of giving patients a copy of their referral letter: randomised controlled trial. BMJ 1999;318:1392-5.

Hildebrandt 1975 \{published data only\}

Hildebrandt D, Davis J. Home visits: a method of reducing the pre-intake dropout rate. Journal of Psychiatric Nursing \& Mental Health Services 1975;13(5):43-4.

Hochstadt 1980 \{published data only\}

Hochstadt N, Trybula J. Reducing missed initial appointments in a community mental health center. Journal of Community Psychology 1980;8:261-5.

\section{Hornung 1998 \{published data only\}}

Hornung WP, Klingberg S, Feldmann R, Schonauer K, Schulze Monking $\mathrm{H}$. Collaboration with drug treatment by schizophrenic patients with and without psychoeducational training: results of a one-year follow-up. Acta Psychiatrica Scandinavica 1998;97(3):213-9.

\section{Joshi 1986 \{published data only\}}

Joshi P, Maisami M, Coyle J. Prospective study of intake procedures in a child psychiatry clinic. Journal of Clinical Psychiatry 1986;47:111-3.

\section{Kourany 1990 \{published data only\}}

Kourany R, Garber J, Tornusciolo. Improving first appointment attendance rates in child psychiatry outpatient clinic. Journal of the American Academy of Child and Adolescent Psychiatry 1990;29(4):657-60.

Larsen 1979 \{published and unpublished data\}

Larsen D, Nguyen TD, Green RS, Attkisson CC. Enhancing client utilisation of community mental health out-patient services. New York: Human Science Press, 1983.

Larsen DL. Enhancing client utilization of community mental health outpatient services. Univ. of Kansas, 1978.

\section{MacDonald 2000 \{published and unpublished data\}}

MacDonald J, Brown N, Ellis P. Telephone prompting improves attendance at community mental health centres - provided the telephone is answered (as supplied 2000). Data on file.

* MacDonald J, Brown N, Ellis P. Using telephone prompts to improve initial attendance at a community mental health centre. Psychiatric Services 2000;51(6):812-4.

\section{O'Loughlin 1990 \{published data only\}}

O'Loughlin S. The effect of a pre-appointment questionnaire on clinical psychologist attendance rates. British Journal of Medical Psychology 1990;63:5-9. 
Pang 1996 \{published data only\}

Pang AHT, Lum FCK, Ungvari GS, Wong CK, Leung YS. A prospective outcome study of patients missing regular psychiatric outpatient appointments. Social Psychiatry and Psychiatric Epidemiology 1996;31:299-302.

Sharma 1995 \{published data only\}

Sharma S, Elkins D, Sicklee A, Roberts C. Effect of pre-discharge interventions on aftercare attendance: process and outcome. Health and Social Work 1995;20(1):15-20.

\section{Sladden 1999 \{published data only\}}

Sladden M, Thomson A. An evaluation of a surveillance system for patients discharged from the acute psychiatry unit in southern Tasmania. Australian and New Zealand Journal of Psychiatry 1999;33:385-91.

\section{Spooren 1998 \{published and unpublished data\}}

Spooren D, Heeringen V, Jannes C. Strategies to increase compliance with out-patient aftercare among patients referred to a psychiatric emergencies department: a multicentre controlled intervention study. Psychological Medicine 1998;28:949-56.

\section{Thi Phan 1995 \{published data only\}}

Thi Phan T. Enhancing client adherence to psychotropic medication regiments: a psychosocial nursing approach. International Journal of Psychiatric Nursing Research 1995;2(1):147-72.

\section{Turner 1976 \{published data only\}}

Turner AJ, Vernon JC. Prompts to increase attendance in a community mental health centre. Journal of Applied Behaviour Analysis 1976;9(2):141-5.

\section{Zanjani 2008 \{published data only\}}

Zanjani F, Miller B, Turiano N, Ross J, Oslin D. Effectiveness of telephone-based referral care management, a brief intervention to improve psychiatric treatment engagement. Psychiatric Services 2008;59(7):776-81.

\section{References to studies awaiting assessment}

\section{Crespo-Iglesias 2006 \{published data only\}}

Crespo-Iglesias JM, Gonzalez Garcia A, Santos Miguelez B, Naya Fernandez S. Improvement of the attendance to the first psychiatric appointments after telephone reminder [Mejoria de la asistencia a las primeras citas en psiquiatria tras aviso telefonico]. Anales de Psiquiatria 2006;22(3):95-101. [MEDLINE: 1254142]

\section{ISRCTN27704027 2011 \{published data only\}}

ISRCTN27704027. Mobile telephone text messages to encourage compliance with medication and to follow up with people with psychosis: A multi-centre randomised controlled two armed trial. http://isrctn.org/ISRCTN27704027 2011.
Sharifi 2008 \{published data only\}

Sharifi V, Alaghband-rad J, Mottaghipour Y, Shahrivar Z, Amini H, Mahmoudi-gharaei J, et al. Effectiveness of specialized services for first-episode psychosis in Iran: a 12-month randomized controlled trial. Early Intervention in Psychiatry 2008;2(Suppl 1):A30.

Velligan 2010 \{published data only\}

Velligan DI, Maples NJ, Castillo D. Novel adherence interventions: effectiveness and translation. Schizophrenia Research 2010;117(2-3):176-7.

\section{Additional references}

\section{Altman 1996}

Altman DG, Bland JM. Detecting skewness from summary information. BMJ 1996;313:1200.

\section{Barnard 1998}

Barnard EJ, Gagiano CA, Joubert G. Patients with chronic mental illness attending outpatient groups - factors influencing compliance. South African Medical Journal 1998;88(6):S1.

\section{Bland 1997}

Bland JM. Statistics notes. Trials randomised in clusters. BMJ 1997;315:600.

\section{Commander 1997}

Commander M, Sashi Dharan S, Odell S, Surtees P. Access to mental health care in an inner-city health district: pathways into and within specialist psychiatric services. British Journal of Psychiatry 1997;170:312-6.

\section{Divine 1992}

Divine GW, Brown JT, Frazier LM. The unit of analysis error in studies about physicians' patient care behavior. Journal of General Internal Medicine 1992;7(6):623-9.

\section{DoH 1998}

Department of Health. Modernising mental health services: safe, sound and supportive. London: HMSO, 1998.

\section{Donner 2002}

Donner A, Klar N. Issues in the meta-analysis of cluster randomized trials. Statistics in Medicine 2002;21:2971-80.

\section{Egger 1997}

Egger M, Davey-Smith G, Schneider M, Minder C. Bias in meta-analysis detected by a simple, graphical test. $B M J$ 1997;315:629-34.

\section{Elbourne 2002}

Elbourne D, Altman DG, Higgins JPT, Curtina F, Worthingtond HV, Vaile A. Meta-analyses involving crossover trials: methodological issues. International Journal of Epidemiology 2002;31(1):140-9.

NCT01473550 2011 \{published data only\}

NCT01473550. Mental health engagement network (mhen). http://ClinicalTrials.gov/show/NCT01473550 2011. 


\section{Giuffrida 1997}

Giuffrida A, Torgerson D. Should we pay the patient? Review of financial incentives to enhance patient compliance. BMJ 1997;315:703-7.

\section{Gulliford 1999}

Gulliford MC. Components of variance and intraclass correlations for the design of community-based surveys and intervention studies: data from the Health Survey for England 1994. American Journal of Epidemiology 1999;149:876-83.

\section{Hershorn 1993}

Hershorn M. The elusive population: characteristics of attendees versus non-attendees for community mental health centre intakes. Community Mental Health Journal 1993;29(1):49-57.

\section{Higgins 2002}

Higgins JPT, Thompson SG. Quantifying heterogeneity in a meta-analysis. Statistics in Medicine 2002;21:1539-58.

\section{Higgins 2008}

Higgins JPT, Green S (editors). Cochrane Handbook for Systematic Reviews of Interventions Version 5.0.1 [updated September 2008] The Cochrane Collaboration, 2008. Available from www.cochrane-handbook.org.

\section{Higgins 2009}

Higgins JPT, Green S (editors). Cochrane Handbook for Systematic Reviews of Interventions 5.0.2 [updated September 2009] The Cochrane Collaboration, 2009. Available from www.cochrane-handbook.org/. Chichester, UK: John Wiley and Sons, Ltd..

\section{Killaspy 1999}

Killaspy H, Banerjee S, King M, Lloyd M. Non-attendance at psychiatric outpatient clinics: communication and implications for primary care. British Journal of General Practice 1999;49:880-8.

\section{Killaspy 2000}

Killaspy H, Banerjee S, King M, Lloyd M. Prospective controlled study of psychiatric out-patient non-attendance: characteristics and outcome. British Journal of Psychiatry 2000;76:160-5.

\section{Little 1991}

Little B, Cannon C, Whitson B, Jarolin D. The failed appointment. Journal of the Oklahoma State Medical Association 1991;84(9):455-8.

\section{Marshall 2000}

Marshall M, Lockwood A, Bradley C, Adams C, Joy C, Fenton M. Unpublished rating scales: a major source of bias in randomised controlled trials of treatments for schizophrenia. British Journal of Psychiatry 2000;176:249-52.

\section{Mechanic 1997}

Mechanic D. Organisation of care and quality of life of persons with serious and persistent mental illness. In: Kastschnig $\mathrm{H}$, Freeman H, Sartorius N editor(s). Quality of life in mental disorders. London: Wiley, 1997.

\section{Moher 2001}

Moher D, Schulz KF, Altman DG. The CONSORT statement: revised recommendations for improving the quality of reports of parallel-group randomised trials. The Lancet 2001;357(9363):1191-94.

\section{NHS 1995}

National Health Service Committee of Public Accounts. 42nd report on outpatients services in England and Wales. London: HMSO, 1995.

\section{Reda 2001}

Reda S, Makhoul S. Prompts to encourage appointment attendance for people with serious mental illness. Cochrane Database of Systematic Reviews 2001, Issue 2. [DOI: 10.1002/14651858.CD002085]

\section{Smoller 1998}

Smoller J, McLean R, Otto M, Pollack M. How do clinicians respond to patients who miss appointments?. Journal of Clinical Psychiatry 1998;59(6):330-8.

\section{Turner 1998}

Turner N. Hyper Guide to the Mental Health Act. http:// www.hyperguide.co.uk/mha 1998.

\section{Tyrer 1999}

Tyrer P, Coid J, Simmonds S, Joseph P, Marriott S. Community mental health teams for people with severe mental illness and disordered personality. Cochrane Database of Systematic Reviews 1999, Issue 2. [DOI: 10.1002/14651858.CD000270.pub2]

\section{Ukoumunne 1999}

Ukoumunne OC, Gulliford MC, Chinn S, Sterne JAC, Burney PGJ. Methods for evaluating area-wide and organisation-based intervention in health and health care: a systematic review. Health Technology Assessment 1999;3(5):1-75.

\section{Xia 2007}

Xia J, Adams CE, Bhagat N, Bhagat V, Bhoopathi P, El-Sayeh H, Pinfold V, Takriti Y. The Leeds Outcomes Stakeholders Survey (LOSS) Study. Proceedings of the 15th Cochrane Colloquium; 2007 Oct 23-27; Sao Paulo. 2007.

* Indicates the major publication for the study

\section{CHARACTERISTICS OF STUDIES}

Characteristics of included studies [ordered by study ID] 
Burgoyne 1983

\begin{tabular}{|c|c|c|}
\hline Methods & \multicolumn{2}{|c|}{$\begin{array}{l}\text { Allocation: randomised - by table of random numbers. } \\
\text { Blindness: not blind. } \\
\text { Duration: } 2 \text { weeks. }\end{array}$} \\
\hline Participants & \multicolumn{2}{|c|}{$\begin{array}{l}\text { Diagnosis: not specified. } \\
\mathrm{N}=690 . \\
\text { Age: adults. } \\
\text { Sex: unspecified. } \\
\text { History: first appointment } 2 \text { days hence, clinic for adult services. }\end{array}$} \\
\hline Interventions & \multicolumn{2}{|c|}{$\begin{array}{l}\text { 1. Prompt: telephone prompt: } 2 \text { days before first appointment. } \mathrm{N}=339 \text { (184 with phone). } \\
\text { 2. Control: no telephone call. } \mathrm{N}=351 \text { ( } 188 \text { with phone). }\end{array}$} \\
\hline Outcomes & \multicolumn{2}{|l|}{ Attendance. } \\
\hline Notes & \multicolumn{2}{|c|}{${ }^{*}$ Outcomes for sub-group of those with telephones also reported and these data presented. } \\
\hline \multicolumn{3}{|l|}{ Risk of bias } \\
\hline Bias & Authors' judgement & Support for judgement \\
\hline $\begin{array}{l}\text { Random sequence genera- } \\
\text { tion (selection bias) }\end{array}$ & Low risk & Using a book of random numbers. \\
\hline $\begin{array}{l}\text { Allocation concealment } \\
\text { (selection bias) }\end{array}$ & High risk & $\begin{array}{l}\text { Allocation not concealed from research assistant who allocated to groups and } \\
\text { made the prompt telephone calls. }\end{array}$ \\
\hline $\begin{array}{l}\text { Blinding (performance } \\
\text { bias and detection bias) } \\
\text { All outcomes }\end{array}$ & Unclear risk & Not discussed. \\
\hline $\begin{array}{l}\text { Incomplete outcome data } \\
\text { (attrition bias) } \\
\text { All outcomes }\end{array}$ & Low risk & All participants included in analysis. \\
\hline $\begin{array}{l}\text { Selective reporting (re- } \\
\text { porting bias) }\end{array}$ & Low risk & All outcomes reported for each group. \\
\hline Other bias & High risk & $\begin{array}{l}\text { Data likely skewed to show smaller effect of telephone prompts due to low } \\
\text { prevalence of telephone ownership in this study population. }\end{array}$ \\
\hline
\end{tabular}

Kitcheman 2008

$\begin{array}{ll}\text { Methods } & \text { Allocation: randomised - by online computer program using small block allocation. } \\ & \text { Blindness: single - data collectors blind, participants and clinic staff blind. } \\ & \text { Duration: } 1 \text { year. } \\ \text { Participants } & \text { Diagnosis: mixture of serious mental illness (126), substance misuse, other non-psychotic disorders. } \\ \text { N=764 (126 serious mental illness). } \\ \text { Age: adult, demographics not given for subgroups. For whole study average age (SD) for prompts and } \\ \text { no prompts groups were } 36.6 \text { years (12.6) and 36.5 years (11.1) respectively. } \\ \text { Sex: data not broken down into subgroups. For whole study M:F prompts and no prompts were 206:182 } \\ \text { and 195:181 respectively. } \\ \text { History: people attending the general adult outpatient clinic for the first time in an urban population in } \\ \text { the north of England. }\end{array}$


Kitcheman 2008 (Continued)

Interventions
1. Prompt: an individualised pro-forma letter ('orientation statement') sent from central administration office 72 hours prior to the first appointment + standard care. $\mathrm{N}=70$.

2. Standard care: this involved ensuring the person wanted to attend psychiatric clinics and sending appointment by post, up to months before date of appointment. $\mathrm{N}=56$.

Outcomes
Attendance: failure to attend the prearranged first appointment
Unable to use:
$\begin{aligned} & \text { Death: not reported for sub-group. } \\ & \text { Use of health services at } 1 \text { year: not reported by sub-group. }\end{aligned}$
Notes
$\begin{aligned} & \text { Study commenced in General adult clinic and the expanded to other clinics when unable to recruit par- } \\ & \text { ticipants as expected. }\end{aligned}$

\section{Risk of bias}

\begin{tabular}{|c|c|c|}
\hline Bias & Authors' judgement & Support for judgement \\
\hline $\begin{array}{l}\text { Random sequence genera- } \\
\text { tion (selection bias) }\end{array}$ & Low risk & Using an on-line computer program. \\
\hline $\begin{array}{l}\text { Allocation concealment } \\
\text { (selection bias) }\end{array}$ & Low risk & Allocation concealed to all researchers but trial co-ordinator. \\
\hline $\begin{array}{l}\text { Blinding (performance } \\
\text { bias and detection bias) } \\
\text { All outcomes }\end{array}$ & Unclear risk & Blinding to patients and clinic staff and those collecting data. \\
\hline $\begin{array}{l}\text { Incomplete outcome data } \\
\text { (attrition bias) } \\
\text { All outcomes }\end{array}$ & Low risk & $\begin{array}{l}\text { Quote: "We were able to acquire all but one record for the primary outcome". } \\
\text { It is not clear which subgroup this record belonged to. Unlikely to have a signif- } \\
\text { icant effect on results. }\end{array}$ \\
\hline $\begin{array}{l}\text { Selective reporting (re- } \\
\text { porting bias) }\end{array}$ & Low risk & Clearly reported all outcomes. \\
\hline Other bias & Low risk & No indication of other biases. \\
\hline
\end{tabular}

\section{Kluger 1983}

$\begin{array}{ll}\text { Methods } & \text { Allocation: randomised through "a random list of treatment conditions". } \\ \text { Blindness: not described. } \\ \text { Duration: one day. }\end{array}$

Participants

Diagnosis: unspecified.

History: consecutive callers to Adult Outpatient Clinic of CMHT, excluded 'walk-ins' and elderly.

$\mathrm{N}=141$.

Age: mean age 32 .

Sex: $71 \mathrm{M}, 70 \mathrm{~F}$.

Race: $49 \%$ black, $38 \%$ white, $13 \%$ Hispanic and others.

\footnotetext{
Interventions $\quad$ 1. Orientation statement: short paragraph (30s to read), explaining programme, fees, and giving encouragement. $\mathrm{N}=25$.

2. Orientation statement + telephone prompt: 24 hours before first appointment. $\mathrm{N}=41$.

3. Telephone prompt only: 24 hours before appointment. $\mathrm{N}=50$.

4. Control: only appointment time. $\mathrm{N}=25$.
} 
Kluger 1983 (Continued)
Outcomes
Attendance.

Notes

Letter to author written but returned as address is now inaccurate.

\section{Risk of bias}

\begin{tabular}{|c|c|c|}
\hline Bias & Authors' judgement & Support for judgement \\
\hline $\begin{array}{l}\text { Random sequence genera- } \\
\text { tion (selection bias) }\end{array}$ & Unclear risk & $\begin{array}{l}\text { Quote: 'Subjects were randomly assigned'. Consecutive attenders at the clinic } \\
\text { were assigned to a 'random list' of interventions. }\end{array}$ \\
\hline $\begin{array}{l}\text { Allocation concealment } \\
\text { (selection bias) }\end{array}$ & High risk & $\begin{array}{l}\text { Quote: 'A health paraprofessional' allocated the participants to each interven- } \\
\text { tion when they at the clinic using a random list of interventions. }\end{array}$ \\
\hline $\begin{array}{l}\text { Blinding (performance } \\
\text { bias and detection bias) } \\
\text { All outcomes }\end{array}$ & Unclear risk & Not discussed. \\
\hline $\begin{array}{l}\text { Incomplete outcome data } \\
\text { (attrition bias) } \\
\text { All outcomes }\end{array}$ & Low risk & All participants included in analysis. \\
\hline $\begin{array}{l}\text { Selective reporting (re- } \\
\text { porting bias) }\end{array}$ & Low risk & All groups reported on. \\
\hline Other bias & High risk & $\begin{array}{l}\text { The separate analysis of those participants who were allocated to telephone } \\
\text { prompts but could not be contacted by 'phone may have led to a greater effect } \\
\text { size in the telephone prompt groups. }\end{array}$ \\
\hline
\end{tabular}

\section{Swenson 1988}

\begin{tabular}{ll}
\hline Methods & Allocation: randomised - block. \\
& Blindness: not specified. \\
& Duration: 3 days.
\end{tabular}

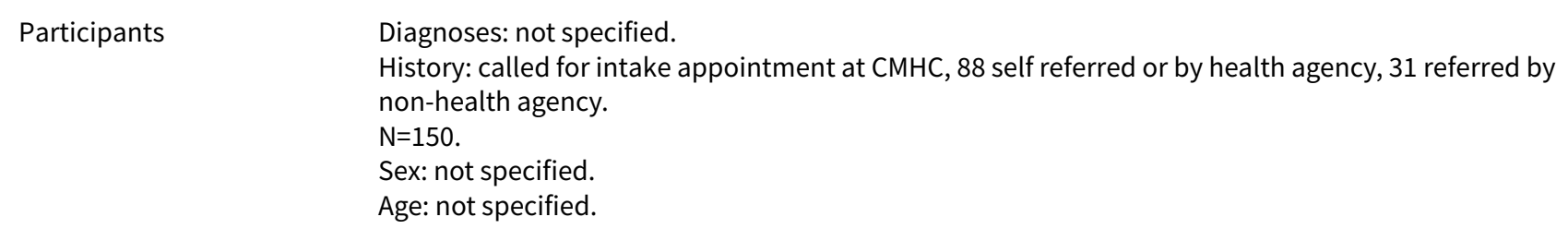

Interventions
2. Letter prompt: one day before appointment. $\mathrm{N}=30$.
3. Letter orientation statement: one day before appointment. $\mathrm{N}=30$.
4. Letter orientation statement: three days before appointment. $\mathrm{N}=30$.
5. Control: appointment card only. $\mathrm{N}=30$.

Outcomes Attendance.

\section{Notes}

\section{Risk of bias}


Swenson 1988 (Continued)

Random sequence genera- Unclear risk Quote: 'Block randomisation' Not discussed further. tion (selection bias)

Allocation concealment $\quad$ Unclear risk Not discussed.
(selection bias)

(selection bias)

Blinding (performance $\quad$ Unclear risk discussed.
bias and detection bias)

All outcomes

Incomplete outcome data Low risk All participants accounted for and included in analysis.
(attrition bias)

All outcomes

Selective reporting (re- Low risk $\quad$ All intended outcomes reported for each group.
porting bias)

Other bias High risk

\begin{abstract}
The participants were clients who phoned themselves to make an appointment which may lead to an artificially high attendance rate. The average waiting time was only eight days so increasing the chances of attending the appointment. The study included children referred to the service so the findings may not be applicable to the general adult population. Appointments on a Monday were excluded which will have an unknown effect on the results.
\end{abstract}

\section{Characteristics of excluded studies [ordered by study ID]}

\begin{tabular}{ll}
\hline Study & Reason for exclusion \\
\hline Bende 1991 & Allocation: not randomised, cohort study. \\
\hline Blake 1990 & $\begin{array}{l}\text { Allocation: randomised (cluster) - weeks, crossover. } \\
\text { Participants: people in long stay psychiatric wards. } \\
\text { Interventions: daily announcement of schedule, posting a list of day's group activities, individual } \\
\text { feedback about attendance versus standard care. } \\
\text { Outcomes: attendance, satisfaction with care. }\end{array}$ \\
\hline
\end{tabular}

\begin{tabular}{ll}
\hline Blouin 1985 & Allocation: not randomised, cohort study. \\
\hline Cramer 1998 & $\begin{array}{l}\text { Allocation: randomised. } \\
\text { Participants: "Axis I diagnoses". } \\
\text { Intervention: "special instruction reinforcing techniques" versus standard care, not primarily fo- } \\
\text { cused on attendance, primarily focused on compliance with drugs. }\end{array}$ \\
\hline
\end{tabular}

$\begin{array}{ll}\text { Danoff } 1993 & \text { Allocation: alternate days. } \\ \text { Participants: children due to attend a paediatric clinic, not people with serious mental illnesses. }\end{array}$

Deane $1991 \quad$ Allocation: not randomised, before and after design.

Hamilton 1999

Allocation: randomised.

Participants: new consultant referrals, only 6/2078 psychiatric problems.

Outcomes: unable to use - data for seriously mentally ill people not analysed separately.

Hildebrandt 1975

Allocation: unclear, "one out of every three families assigned consecutively to the 'home visit' group". 


\begin{tabular}{ll}
\hline Study & Reason for exclusion \\
\hline & $\begin{array}{l}\text { Participants: families due to attend Adolescent Clinic in department of psychiatry, unlikely to be } \\
\text { seriously mentally ill. }\end{array}$
\end{tabular}

\begin{tabular}{ll}
\hline Hochstadt 1980 & $\begin{array}{l}\text { Allocation: randomised. } \\
\text { Participants: children or adolescents due to attend a CMHT, unlikely to be seriously mentally ill. }\end{array}$ \\
\hline Hornung 1998 & $\begin{array}{l}\text { Allocation: randomised. } \\
\text { Participants: people with schizophrenia. } \\
\text { Interventions: psycho-education for people with schizophrenia versus psycho- education and cog- } \\
\text { nitive therapy versus psycho-education for relatives, not focused on attendance. }\end{array}$ \\
\hline
\end{tabular}

\begin{tabular}{ll}
\hline Joshi 1986 & Allocation: not randomised, historical control study. \\
\hline Kourany 1990 & $\begin{array}{l}\text { Allocation: randomised. } \\
\text { Participants: people due to attend for first appointment at child psychiatry clinic, not seriously } \\
\text { mentally ill. }\end{array}$ \\
\hline Larsen 1979 & $\begin{array}{l}\text { Allocation: randomised. } \\
\text { Participants: people with neuroses, not people with schizophrenia. }\end{array}$ \\
\hline MacDonald 2000 & $\begin{array}{l}\text { Allocation: quasi-randomised - odd-even numbers. } \\
\text { Interventions: telephone prompt one day before appointment versus no prompt. } \\
\text { Outcome: attendance at clinic, but data unclear due to 'administrative oversight', and 'staff short- } \\
\text { ages'. Author has already been helpful in providing extra data and further information awaited. }\end{array}$
\end{tabular}

\begin{tabular}{|c|c|}
\hline O'Loughlin 1990 & Allocation: not randomised, consecutive referrals to three different psychologists. \\
\hline Pang 1996 & Allocation: not randomised, survey. \\
\hline Sharma 1995 & $\begin{array}{l}\text { Allocation: randomised (cluster) - three psychiatric units. } \\
\text { Participants: people referred to aftercare group in the three psychiatric inpatient units. } \\
\text { Interventions: appointment + met by outpatient therapist versus appointment + attendance at } \\
\text { group before discharge versus appointment alone. } \\
\text { Outcomes: attendance, but only individual data presented. Data on those who refused to attend } \\
\text { (second group) excluded and no cluster correlation presented. }\end{array}$ \\
\hline
\end{tabular}

\begin{tabular}{ll}
\hline Sladden 1999 & Allocation: not randomised, cohort study. \\
\hline Spooren 1998 & Allocation: randomised. \\
& Participants: people referred to out-patient treatment. \\
& Interventions: a fixed appointment, and a number of interventions in order to allow for a flexible \\
treatment approach including involvement of family, discussion of further treatment with patient & and after-care, counselling to increase motivation and incorporation of patient's perspective ver- \\
& sus standard care, not simple prompt to encourage attendance. (Dr Spooren kindly supplied addi- \\
tional information).
\end{tabular}

\begin{tabular}{ll}
\hline Thi Phan 1995 & Allocation: not randomised, survey. \\
\hline Turner 1976 & $\begin{array}{l}\text { Allocation: not randomised, "sequential experimental design alternating baseline and phone mes- } \\
\text { sage". }\end{array}$ \\
\hline Zanjani 2008 & $\begin{array}{l}\text { Allocation: randomised by computer programme and stratified according to diagnosis. } \\
\text { Interventions: not looking at outpatient appointments. Both groups receiving prompts. }\end{array}$ \\
\hline
\end{tabular}


Characteristics of studies awaiting assessment [ordered by study ID]

Crespo-Iglesias 2006

\section{Methods}

Participants

\section{Interventions}

Outcomes

$$
\text { Notes }
$$

To be assessed.

\section{ISRCTN27704027 2011}

Methods

\section{Participants}

Interventions

\section{Outcomes}

\section{Notes}

To be assessed.

\section{NCT01473550 2011}

\section{Methods}

\section{Participants}

Interventions

\section{Outcomes}

Notes

To be assessed.

Sharifi 2008

\section{Methods}

Participants

\section{Interventions}

\section{Outcomes}


Velligan 2010

Methods

\section{Participants}

Interventions

Outcomes

\section{DATA AND ANALYSES}

Comparison 1. PROMPT TYPE versus NO PROMPT

\begin{tabular}{lllll}
\hline Outcome or subgroup title & $\begin{array}{l}\text { No. of } \\
\text { studies }\end{array}$ & $\begin{array}{l}\text { No. of } \\
\text { partici- } \\
\text { pants }\end{array}$ & Statistical method & Effect size \\
\hline 1 Did not attend appointment & 4 & & Risk Ratio (M-H, Random, 95\% Cl) & Subtotals only \\
\hline 1.1 telephone prompts & 2 & 447 & Risk Ratio (M-H, Random, 95\% Cl) & $0.84[0.66,1.07]$ \\
\hline 1.2 text-based prompts & 3 & 326 & Risk Ratio (M-H, Random, $95 \% \mathrm{Cl})$ & $0.76[0.43,1.32]$ \\
\hline $\begin{array}{l}1.3 \text { combination of telephone } \\
\text { and text-based prompts }\end{array}$ & 1 & 66 & Risk Ratio (M-H, Random, $95 \% \mathrm{Cl})$ & $0.70[0.42,1.17]$ \\
\hline
\end{tabular}

Analysis 1.1. Comparison 1 PROMPT TYPE versus NO PROMPT, Outcome 1 Did not attend appointment.

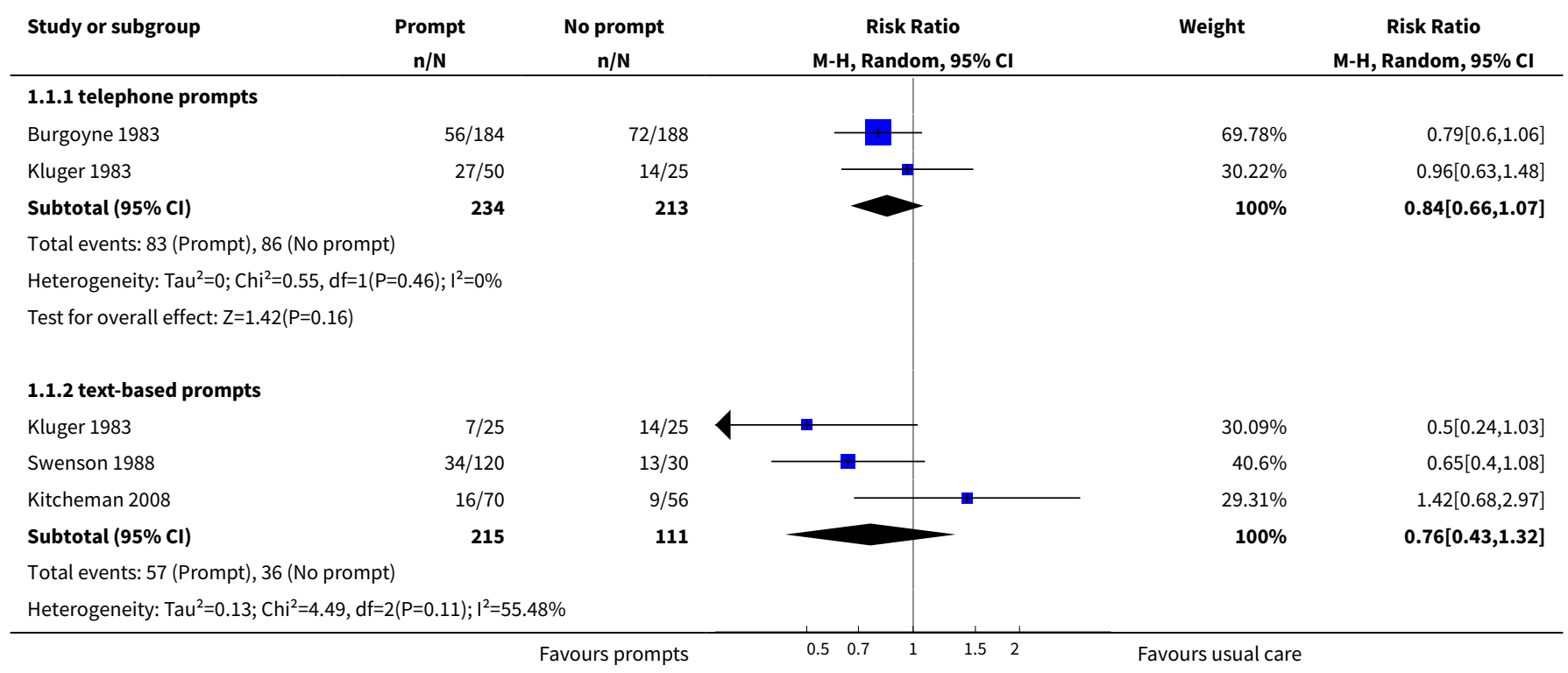




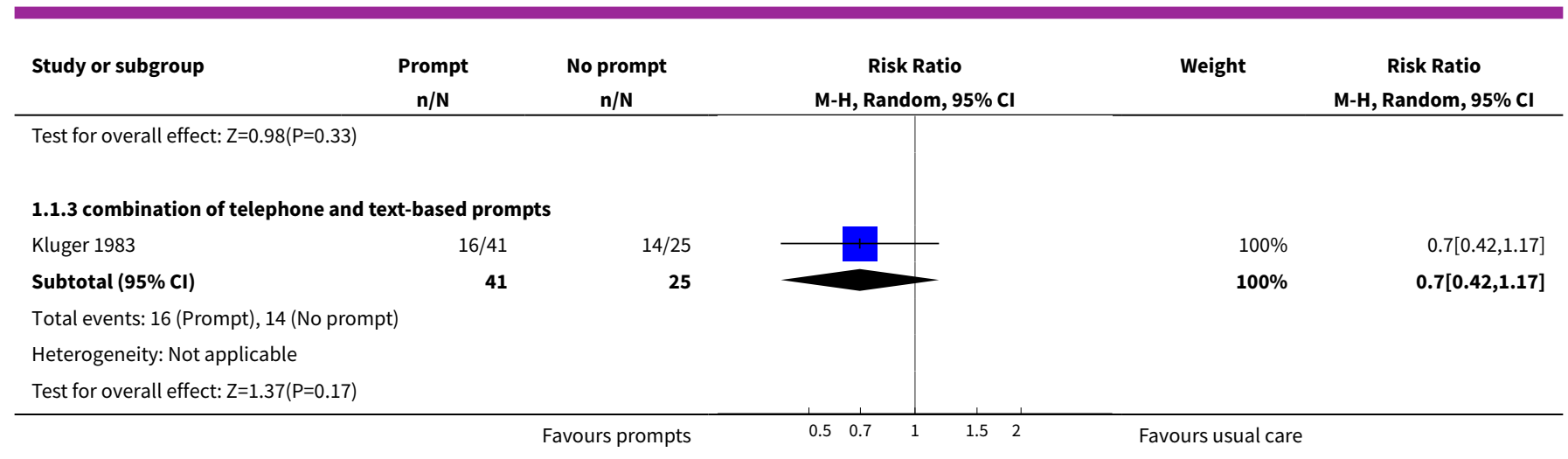

\section{Comparison 2. TELEPHONE PROMPTS versus TEXT-BASED PROMPTS (ORIENTATION STATEMENT)}

\begin{tabular}{lllll}
\hline Outcome or subgroup title & $\begin{array}{l}\text { No. of } \\
\text { studies }\end{array}$ & $\begin{array}{l}\text { No. of partici- } \\
\text { pants }\end{array}$ & Statistical method & Effect size \\
\hline 1 Did not attend appointment & 1 & 75 & Risk Ratio (M-H, Random, 95\% Cl) & $1.93[0.98,3.80]$ \\
\hline
\end{tabular}

Analysis 2.1. Comparison 2 TELEPHONE PROMPTS versus TEXT-BASED PROMPTS (ORIENTATION STATEMENT), Outcome 1 Did not attend appointment.

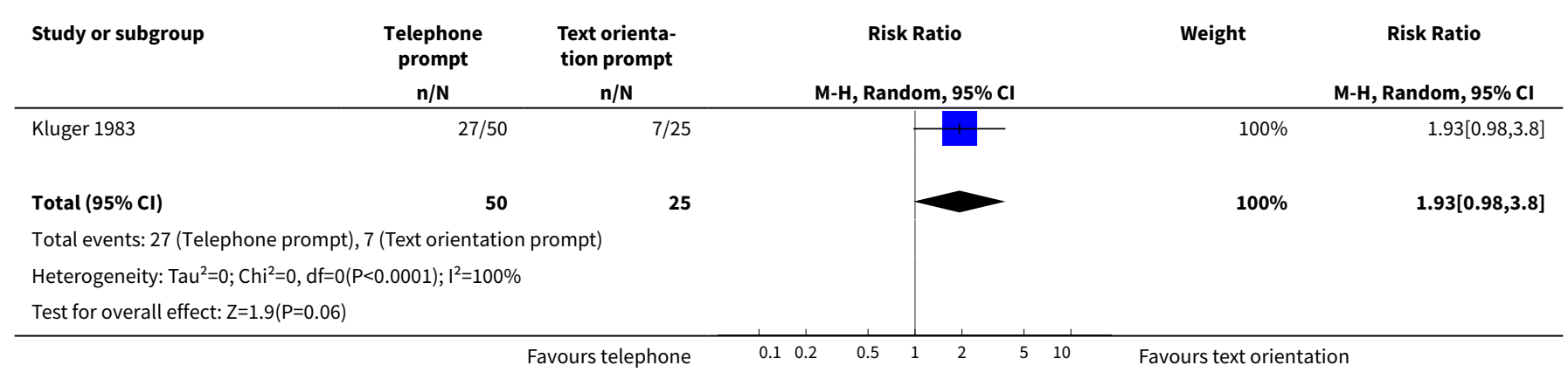

\section{Comparison 3. TEXT LETTER PROMPT versus TEXT ORIENTATION STATEMENT}

\begin{tabular}{llllll}
\hline Outcome or subgroup title & $\begin{array}{l}\text { No. of } \\
\text { studies }\end{array}$ & $\begin{array}{l}\text { No. of } \\
\text { partici- } \\
\text { pants }\end{array}$ & Statistical method & Effect size \\
\hline 1 Did not attend appointment & 1 & & Risk Ratio (M-H, Random, 95\% Cl) & Subtotals only \\
\hline 1.1 any time before appointment & 1 & 120 & Risk Ratio (M-H, Random, 95\% Cl) & $1.62[0.89,2.92]$ \\
\hline 1.2 one day before appointment & 1 & 60 & Risk Ratio (M-H, Random, 95\% Cl) & $2.0[0.78,5.15]$ \\
\hline 1.3 three days before & 1 & 60 & Risk Ratio (M-H, Random, 95\% Cl) & $1.38[0.64,2.93]$ \\
\hline
\end{tabular}


Analysis 3.1. Comparison 3 TEXT LETTER PROMPT versus TEXT ORIENTATION STATEMENT, Outcome 1 Did not attend appointment.

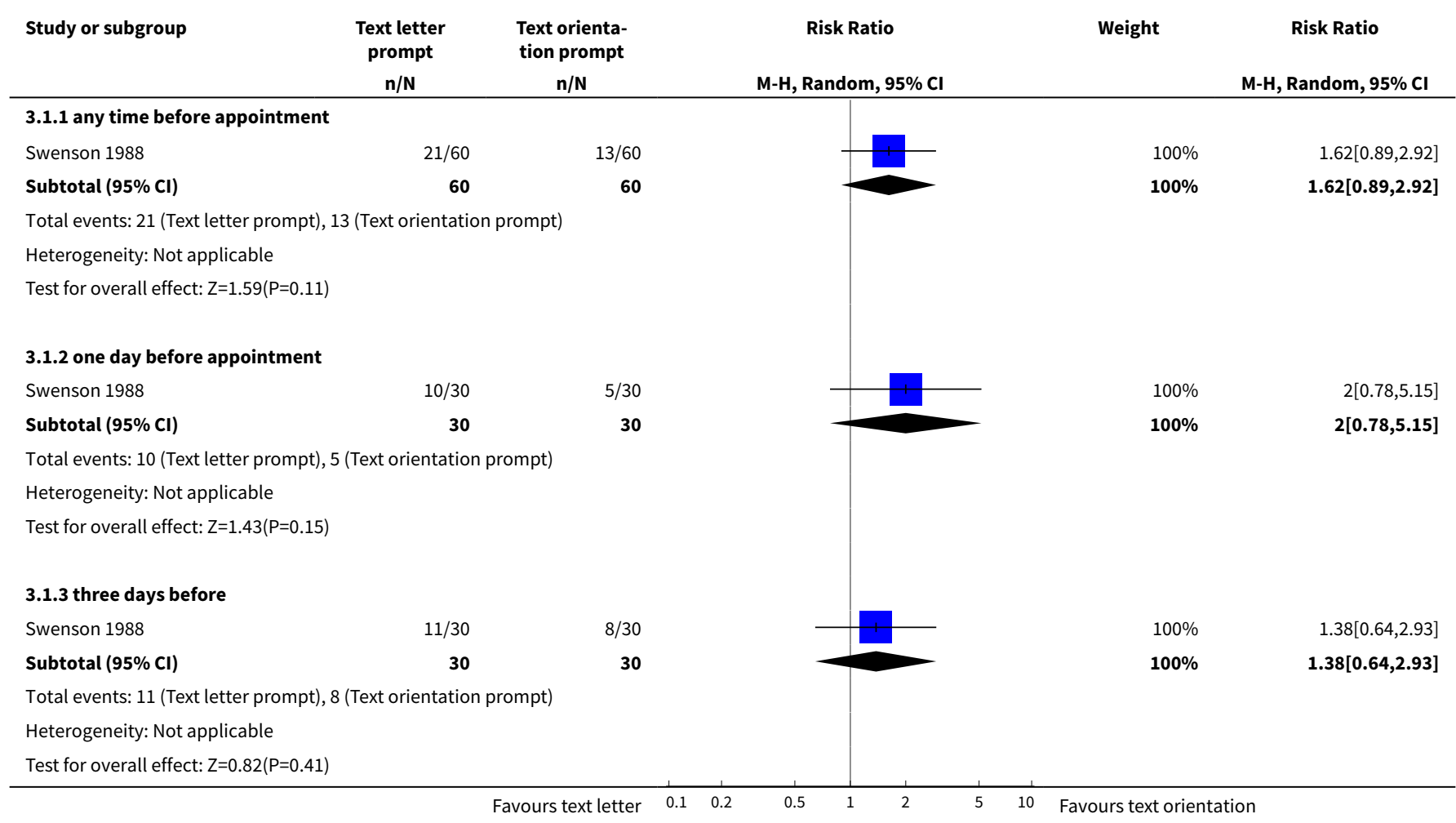

Comparison 4. ANY PROMPT versus NO PROMPT

\begin{tabular}{lllll}
\hline Outcome or subgroup title & $\begin{array}{l}\text { No. of } \\
\text { studies }\end{array}$ & $\begin{array}{l}\text { No. of partici- } \\
\text { pants }\end{array}$ & Statistical method & Effect size \\
\hline 1 Did not attend appointment & 4 & 789 & Risk Ratio (M-H, Random, 95\% Cl) & $0.80[0.65,0.98]$ \\
\hline
\end{tabular}

\section{Analysis 4.1. Comparison 4 ANY PROMPT versus NO PROMPT, Outcome 1 Did not attend appointment.}

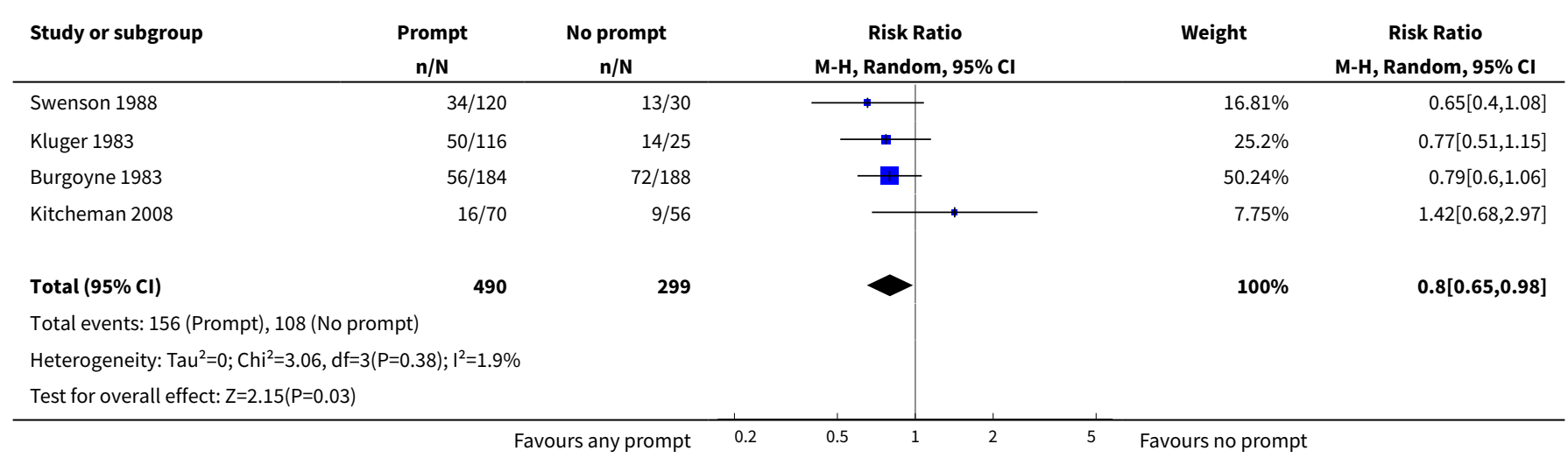




\section{ADDITIONAL TABLES}

\section{Table 1. Suggested design for a study}

\begin{tabular}{|c|c|}
\hline Methods & $\begin{array}{l}\text { Allocation: randomised, clearly described. } \\
\text { Blindness: described and tested. } \\
\text { Duration: } 1 \text { year. }\end{array}$ \\
\hline Participants & $\begin{array}{l}\text { Diagnosis: no specific diagnosis - but recorded clearly. } \\
\mathrm{N}=300+.^{*} \\
\text { Age: any. } \\
\text { Sex: both. } \\
\text { History: people attending out-patient clinics. }\end{array}$ \\
\hline Interventions & $\begin{array}{l}\text { 1. Prompt: could be electronic or letter-based. } \mathrm{N}=150 \\
\text { 2. No prompt: } \mathrm{N}=150 \text {. }\end{array}$ \\
\hline Outcomes & $\begin{array}{l}\text { Attending clinic. } \\
\text { Lost to follow up. } \\
\text { Service use. } \\
\text { Unwelcome events. }\end{array}$ \\
\hline Notes & $\begin{array}{l}\text { * Powered to be able to identify a difference of } 20 \% \text { between groups for primary outcome with ad- } \\
\text { equate degree of certainty. }\end{array}$ \\
\hline
\end{tabular}

\section{APPENDICES}

\section{Appendix 1. Search strategies from previous versions of this review.}

Relevant randomised trials were identified by searching the following electronic databases:

1. Biological Abstracts on Silverplatter WinSPIRS 4.0 (January 1985 to March 2000) was searched using the Cochrane Schizophrenia Group's phrase for randomised controlled trials (see Group search strategy) combined with:

AND [(no?show or (appointment* near6 compliance) or (appointment* near6 fail ${ }^{\star}$ ) or (appointment* near6 keep ${ }^{\star}$ ) or (appointment ${ }^{\star}$ near6

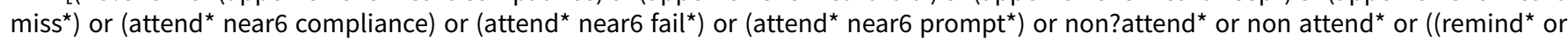
prompt $^{\star}$ or attend ${ }^{\star}$ ) near6 (letter ${ }^{\star}$ or telephone ${ }^{\star}$ or call ${ }^{\star}$ or visit $\left.{ }^{\star}\right)$ ) or (appointment ${ }^{\star}$ near6 prompt $\left.{ }^{\star}\right)$ ]

This downloaded set of reports was searched within the bibliographic package ProCite, with the phrase [schizo* or psych* or mental* or hebephreni* or oligophreni* ${ }^{\star}$ or TARDIV* or DYSKINE* $^{*}$ or diskine ${ }^{\star}$ or AKATHISI ${ }^{\star}$ or ACATHISI* or parkinson* ]

2. CINAHL on Silverplatter WinSPIRS 4.0 (January 1982 to May 2000) was searched using the Cochrane Schizophrenia Group's phrase for randomised controlled trials (see Group search strategy) combined with:

AND [no?show or appointment ${ }^{\star}$ near6 compliance or appointment ${ }^{\star}$ near6 fail ${ }^{\star}$ or appointment ${ }^{\star}$ near6 keep* or appointment ${ }^{\star}$ near6

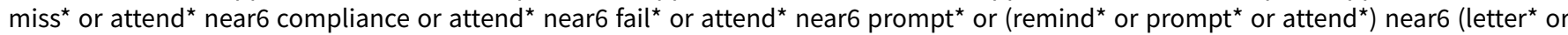
telephone or call ${ }^{\star}$ or visit $\left.{ }^{\star}\right)$ or non?attend ${ }^{\star}$ or non attend ${ }^{\star}$ or appointment ${ }^{\star}$ near6 prompt ${ }^{\star}$ or ((("patient-compliance"/ all subheadings/ all age subheadings) or ("Appointments-and-Schedules"/ all topical subheadings / all age subheadings)) and (("information-system"/ all subheadings/ all age subheadings) or ("telephone"/ all subheadings/ all age subheadings) or ("outpatient-care"/ all subheadings) or ("absenteeism"/ all subheadings/ all age subheadings) or ("motivation"/ all subheadings/ all age subheadings) or ("Outpatient-Service"/ all topical subheadings / all age subheadings)))]

This downloaded set of reports was searched within the bibliographic package ProCite, with the phrase [schizo* or psych or mental* or hebephreni* or oligophreni* or TARDIV* or DYSKINE* or diskine* or AKATHISI* or ACATHISI* or parkinson*

3. Cochrane Schizophrenia Group's Register (June 2000) was searched using the phrase: 
[(appointment ${ }^{\star}$ and (compliance or keep or miss $^{\star}$ or fail $^{\star}$ or prompt pr $\left.^{\star}\right)$ or (attend ${ }^{\star}$ and (compliance or fail or prompt $\left.\left.^{\star}\right)\right)$ or $\left(\left(\right.\right.$ remind $^{\star}$ or prompt $^{\star}$ or attend ${ }^{\star}$ ) and (letter ${ }^{\star}$ or telephone* or visit* or call $\left.{ }^{\star}\right)$ ) or no-show or "no show" or non-attend* or nonattend* or "non attender" or "non attenders" or patient-compliance or reminder-systems or appointments-and-schedues or patient-dropouts or outpatient-clinics or treatment-compliance or client-attitudes or client-characteristics or motivation or telephone-systems or absenteeism or outpatientcare or outpatient-service or "patient compliance" or "reminder systems" or "appointments and schedules" or "patient dropouts" or "outpatient clinics" or "treatment compliance" or "client attitudes" or "client characteristics" or "telephone systems" or "outpatient care" or "outpatient service")]

This downloaded set of reports was searched within the bibliographic package ProCite, with the phrase [schizo* or psych* or mental ${ }^{\star}$ or hebephreni* or oligophreni* or TARDIV* ${ }^{\star}$ or DYSKINE* or diskine $^{\star}$ or AKATHISI* or ACATHISI $^{\star}$ or parkinson ${ }^{\star}$ ]

4. CCTR/CENTRAL on Cochrane Library (Issue 2, 2000) was searched using the phrase:

NON-ATTEND* or (NON next ATTEND*) or NONATTEND* or NO-SHOW* or (APPOINTMENT* and COMPLIANCE) or (APPOINTMENT* and MISS $^{\star}$ ) or (APPOINTMENT ${ }^{\star}$ and FAIL ${ }^{\star}$ ) or (APPOINTMENT ${ }^{\star}$ and PROMPT $^{\star}$ ) or (APPOINTMENT* ${ }^{\star}$ and KEEP*) or (ATTEND* and PROMPT ${ }^{\star}$ ) or ((REMIND* or PROMPT* ${ }^{\star}$ or ATTEND*) next $\left(\right.$ LETTER $^{\star}$ or TELEPHONE* or VISIT* or CALL $\left.{ }^{\star}\right)$ ) or (ATTEND* next COMPLIANCE) or (ATTEND* next FAIL*) or (PATIENT-COMPLIANCE:ME and REMINDER-SYSTEMS:ME or REMINDER-SYSTEMS:ME or TELEPHONE:ME or APPOINTMENTS-ANDSCHEDULES:ME or PATIENT-DROPOUTS:ME or OUTPATIENT-CLINICS-HOSPITAL:ME)

This downloaded set of reports was searched within the bibliographic package ProCite, with the phrase [schizo* or psych* or mental ${ }^{\star}$ or hebephreni* or oligophreni* ${ }^{\star}$ or TARDIV* ${ }^{\star}$ or DYSKINE* or diskine $^{\star}$ or AKATHISI* or ACATHISI $^{\star}$ or parkinson ${ }^{\star}$ ]

5. EMBASE on Silverplatter WinSPIRS 4.0 (January 1980 to June 2000) was searched using the Cochrane Schizophrenia Group's phrase for randomised controlled trials (see Group search strategy) combined with:

AND [no?show or (appointment ${ }^{\star}$ near6 compliance) or (appointment* near6 fail ${ }^{\star}$ ) or (appointment ${ }^{\star}$ near6 keep*) or ( ${ }^{\star}$ appointment ${ }^{\star}$ near6

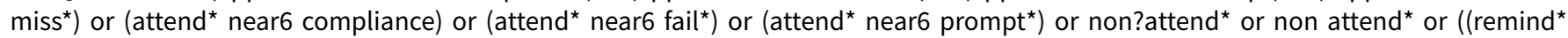
or prompt ${ }^{\star}$ or attend ${ }^{\star}$ ) near6 (letter ${ }^{\star}$ or telephone or call* or visit $\left.{ }^{\star}\right)$ ) or (appointment ${ }^{\star}$ near6 prompt ${ }^{\star}$ ) or (("patient-compliance"/ all subheadings) and ("information-system"/ all subheadings) or ("telephone"/ all subheadings) or ("outpatient-care"/ all subheadings) or ("absenteeism"/ all subheadings) or ("motivation"/ all subheadings))]

This downloaded set of reports was searched within the bibliographic package ProCite, with the phrase [schizo* or psych ${ }^{\star}$ or mental ${ }^{*}$ or

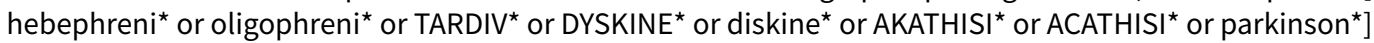

6. MEDLINE on Silverplatter WinSPIRS 4.0 (January 1966 to July 2000) was searched using the Cochrane Schizophrenia Group's phrase for randomised controlled trials (see Group search strategy) combined with:

AND [no?show or (appointment* near6 compliance) or (appointment* near6 fail ${ }^{\star}$ ) or (appointment* near6 keep*) or (*appointment* near6 miss $^{\star}$ ) or (attend ${ }^{\star}$ near6 compliance) or (attend $d^{\star}$ near6 fail $\left.{ }^{\star}\right)$ or (attend $d^{\star}$ near6 prompt ${ }^{\star}$ ) or non?attend ${ }^{\star}$ or non attend ${ }^{\star}$ or $\left(\left(\right.\right.$ remind $^{\star}$ or prompt $^{\star}$ or attend $\left.{ }^{\star}\right)$ near6 (letter or telephone or call $^{\star}$ or visit*)) or (appointment ${ }^{\star}$ near6 prompt $\left.{ }^{\star}\right)$ or (("Appointments-and-Schedules") and (("Reminder-Systems"/ all subheadings) or ("Patient-Compliance"/ all subheadings) or (explode "Telephone"/ all subheadings) or ("Patient-Dropouts"/ all subheadings) or ("Outpatient-Clinics-Hospital"/ all subheadings)))]

This downloaded set of reports was searched within the bibliographic package ProCite, with the phrase [schizo* or psych* or mental* or

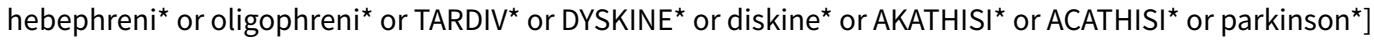

7. PsycLIT on Silverplatter WinSPIRS 4.0 (January 1887 to June 2000) was searched using the Cochrane Schizophrenia Group's phrase for randomised controlled trials (see Group search strategy) combined with:

AND [no?show or (appointment* near6 compliance) or (appointment* near6 fail ${ }^{\star}$ ) or (appointment ${ }^{\star}$ near6 keep*) or ( ${ }^{\star}$ appointment ${ }^{\star}$ near6

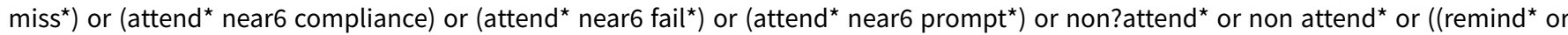
prompt $^{\star}$ or attend $\left.{ }^{\star}\right)$ near6 (letter* or telephone or call ${ }^{\star}$ or visit $\left.\left.{ }^{\star}\right)\right)$ or (appointment ${ }^{\star}$ near6 prompt $\left.^{\star}\right)$ or ((("Treatment-Compliance" in DE) or ("Outpatient-Treatment" in DE) or ("Treatment-Refusal" in DE)) and (("Treatment-Dropouts" in DE) or ("Client-Attitudes" in DE) or ("ClientCharacteristics" in DE) or ("Motivation-" in DE) or ("Telephone-Systems" in DE)))]

This downloaded set of reports was searched within the bibliographic package ProCite, with the phrase [schizo* or psych* or mental* or hebephreni* or oligophreni* or TARDIV* ${ }^{\star}$ or DYSKINE* or diskine* or AKATHISI* or ACATHISI* or parkinson $\left.{ }^{\star}\right]$

\section{WHAT'S NEW}




\begin{tabular}{lll}
\hline Date & Event & Description \\
\hline 17 May 2012 & Amended & $\begin{array}{l}\text { Update search using Cochrane Schizophrenia Group's Trial Reg- } \\
\text { ister carried out, 5 studies added to awaiting classification. }\end{array}$ \\
\hline
\end{tabular}

\section{HISTORY}

Protocol first published: Issue 2, 2000

Review first published: Issue 2, 2001

\begin{tabular}{lll}
\hline Date & Event & Description \\
\hline 18 January 2012 & Amended & Contact details updated. \\
\hline 22 January 2010 & New search has been performed & Updated to new format and to include new trial. \\
\hline
\end{tabular}

\section{CONTRIBUTIONS OFAUTHORS}

Sawsan Reda - Protocol preparation, searching, trial selection, data extraction, completion of original version of review and help with completion of current version.

Matthew Rowett - Trial agreement, data agreement, data extraction, completion of updated review.

Samer Makhoul - Protocol writing, trial agreement, data agreement, help with completion of review, all for original version.

\section{DECLARATIONS OF INTEREST}

Both Dr Reda and Dr Makhoul are of the opinion at the time of completion of the protocol for this review that prompts do increase attendance and compliance with medication. Dr Rowett is of the opinion that any prompt is likely to increase the rate of attendance, although this increase may be small.

\section{SOURCES OF SUPPORT}

\section{Internal sources}

- University of Surrey, UK.

- Damascus University, Syrian Arab Republic.

\section{External sources}

- No sources of support supplied

\section{DIFFERENCES BETWEEN PROTOCOLAND REVIEW}

This version of the review has substantially changed the protocol from the original, (Reda 2001). This is in keeping with improvements in methodology as well as the reformatting demanded by upgrade into RevMan 5. Even though the text has changed considerably we do not feel that this is likely to make a substantial difference to the overall results as data have been handled as they were before in the earlier version.

The other difference between protocol and review is use of the Number Needed To Treat (NNT) statistic. As this has been largely superseded by the data in the Summary of Findings tables we have not calculated NNT for specific results.

\section{IN DEX TERMS}

\section{Medical Subject Headings (MeSH)}

*Appointments and Schedules; *Mental Disorders; *Patient Compliance; *Reminder Systems; Randomized Controlled Trials as Topic; Schizophrenia 


\section{MeSH check words}

Humans 